\title{
A $C^{1}$ FINITE ELEMENT FAMILY FOR KIRCHHOFF PLATE BENDING
}

\author{
J. TORRLS, A. SAMARTÍN, V. ARROYO AND J. DIAZ. DEL VALLE
}

Departamento de Análisis de las Estructuras. Escuela Técnica Superior de Ingenieros de Caminos Universidad de Cantabria. Santander. Spain

\section{SUMMARY}

After a short introduction the possibilities and limitations of polynomial simple elements with $C^{1}$ continuity are discussed with reference to plate bending analysis. A family of this kind of elements is presented. These elements are applied to simple cases in order to assess their computational efficiency. Finally some conclusions are shown, and future research is also proposed.

\section{INTRODUCTION}

The application of the finite element method (F-E-M) to the analysis of Kirchhoff plate bending demands the continuity in the first derivative of the expansion of the deflection $w$. The reader is referred to Zicnekiewicz's excellent book ${ }^{1}$ for details.

The types of elements which satisfy this condition are referred to in the literature as conforming or compatible elements. However, it has been shown in References 2 and 3, that it is occasionally possible to obtain highly efficient converging results (with respect to the energy form) with nonconformingelements. This convergence, which in such cases may not be monotonic, may depend on the mesh configuration of finite elements, i.e. in some examples there may not be convergence. Irons ${ }^{+}$thus proposed his well-known patch test, that works for all 'non pathological' situations. ${ }^{5}$

For bending compatible finite elements two important aspects of convergence--monotony and mesh independence - can be ensured without further tests, which in some cases are of practical and theoretical interest. However, the task of constructing conforming bending elements is not an easy one. In fact it is not possible to achieve $C^{1}$ conformity in simple elements by using polynomial expressions with unique expressions in their interior. ${ }^{6}$ The several techniques developed up to this date for obtaining compatible elements 7 10 can be divided into two types, those considering $C^{1}$ compatibility and those avoiding it.

With $C^{0}$ there is no problem with the value of the second mixed derivative ( $\left.w_{* x}\right)$ at the corners.

The second mixed derivative $\left(w_{x y}\right)$ at the corners of the elements can be a function of other degrees of freedom (slave d.o.f.), or itself another degree of freedom (master d.o.f.). If the first case is considered, and only first derivatives are taken as master d.o.f.s at the corners, there are two possibilities to consider: (1) rational correcting functions and (2) division of the elements into areas (Figure 1).

Among the four types of solution shown in Figure 1, this paper deals with piecewise functions which, in addition to the general advantages of the FEM. provide a unified solution, easy changes of mesh ( $h$-convergence). easy to impose boundary conditions and a symmetric 


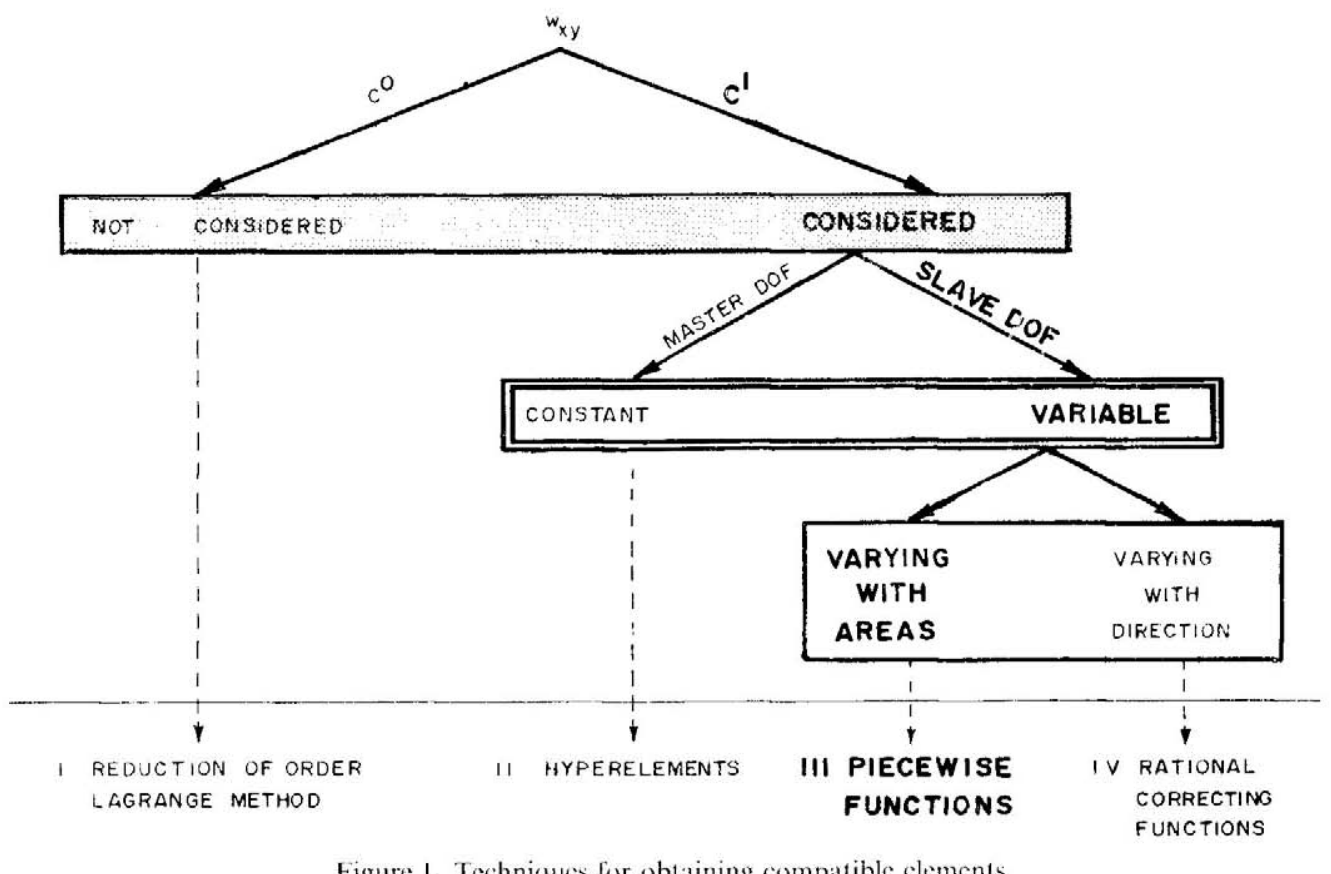

banded matrix - and with $C^{1}$ clements about which, in addition to the advantages monotonous convergence and mesh independence it must be said that

1. The numerical integration can be very accurate because it is used in polynomials.

2. The extension to shells has no problems, so that the elements used are simple. ${ }^{11}$

A general procedure is proposed to construct the shape functions. so that an element family is achieved. In this way by varying the interpolation functions with the same mesh the accuracy is improved $\left(h^{k}\right.$-convergence).

In the following a hicrarchic family of $C^{1}$ elements based on the application of piecewise polynomials will be described. These piccewise polynomials were first used by Clough and Tocher ${ }^{12}$ in triangular elements, and extended later to parallelograms by Clough and Felippa. ${ }^{1.3}$ Triangular elements have also been used by Clough and Felippa. ${ }^{13}$

\section{HIERARCHIC FAMILY}

\section{Introductory example}

In order to grasp the main features of the family of triangular finite elements, the member corresponding to the polynomial order $N=5$ will be considered.

The triangular element is divided into another three as is shown in Figure 2, where for simplicity ' 13 ' is the centre of gravity. In each of these subelements a complete polynomial interpolation function of degree 5 is built (Figure 2).

The number of degrees of freedom (d.o.f.) and their distribution along external and internal sides will be discussed. In each subelement 21 d.o.f. exist, corresponding to the number of polynomial coefficients. Along its external side the $C^{0}$ continuity is ensured by 6 d.o.f. and the $C^{1}$ continuity (first derivative in the normal direction to the side) demands 5 d.o.f. At each external corner there are only 3 d.o.f., namely $w, \partial w / \hat{r} x, \partial w / \partial y$, because the element is simple. 


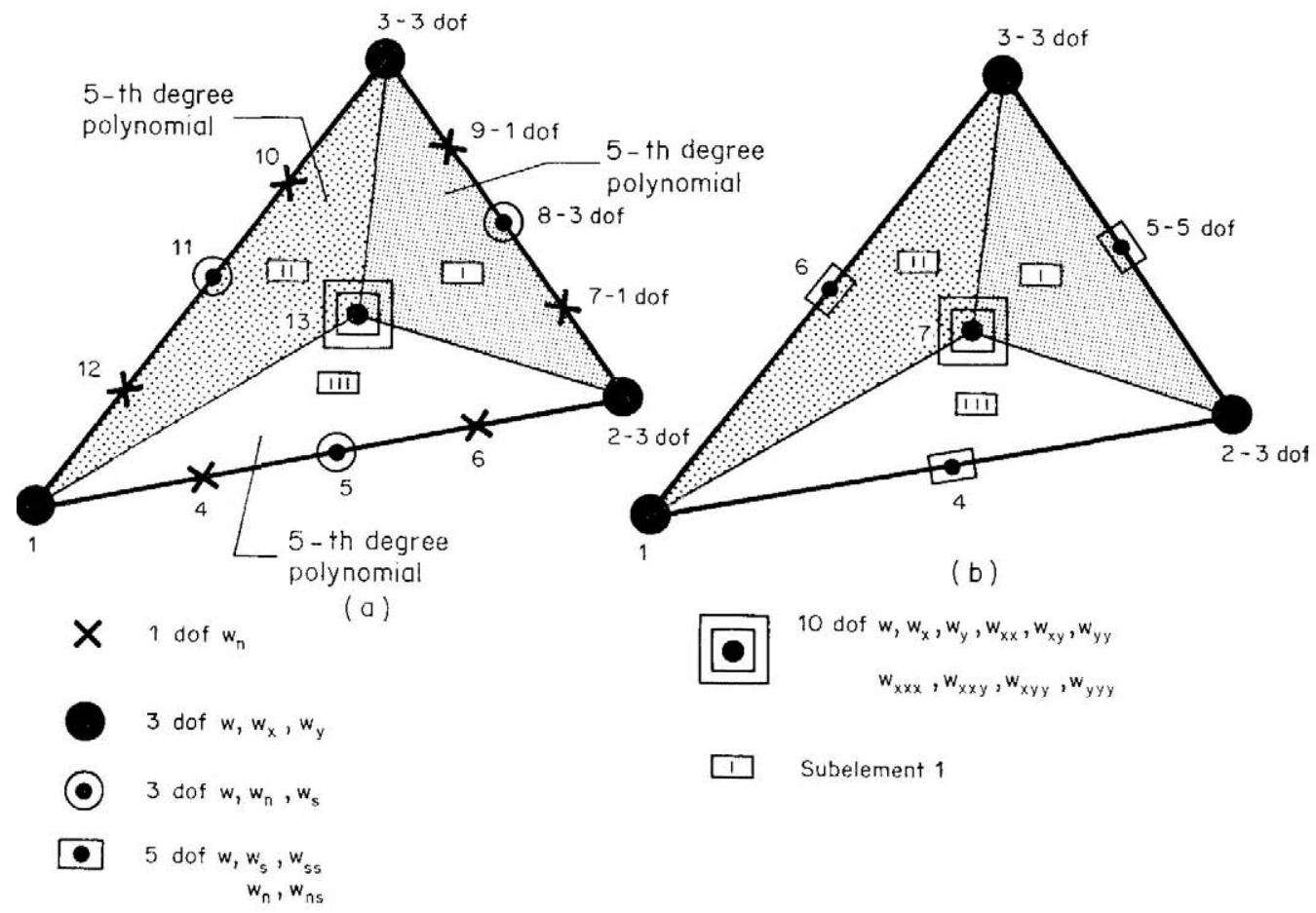

Figure 2. Two possible distributions of d.o.f. along the external sides of the 5 th degree element

This means that 2 d.o.f. $(w, \partial w / \partial s)$ and 1 d.o.f. $(\partial w / \partial n)$ can be taken into account in the $C^{0}$ and $C^{1}$ continuity, respectively, along the external side. Then along this side, $2(=6-2 \times 2)$ d.o.f. and $3(=5-2 \times 1)$ d.o.f. for $C^{0}$ and $C^{1}$ continuity have to be considered (Figures 3(b), (c)), i.e. a total of 5 d.o.f. and therefore only $10(=21-5 \times 3)$ internal d.o.f. remain (Figure 2).

It is interesting to point out that several possibilities exist for placing the $5(=2+3)$ d.o.f. along the external side. All of them represent the same complete polynomial along the side and give identical approximation levels. ${ }^{14}$ One corresponds to using only first derivatives along the side and is shown in Figure 2(a). Another possibility, perhaps the most simple one, is to concentrate all the $5(=2+3)$ d.o.f. at the midside node (Figure 2(b)).

A similar reasoning to the previous one allows us to concentrate the 10 remaining internal d.o.f. namely $w, \partial w / \partial x, \partial w / \partial y, \partial^{2} w / \partial x^{2}, \ldots, \partial^{3} w / \partial y^{3}$ (Figure 2) at the node 0 . Then the continuity along each internal side will be analysed. First, $C^{0}$ continuity demands 6 d.o.f., but already at its two end nodes 6 d.o.f. $=2$ d.o.f. $(w, \partial w / \partial s)+4$ d.o.f. $\left(w, \partial w / \partial s, \partial^{2} w / \partial s^{2}, \partial^{3} w / \partial s^{3}\right)$ exist (Figure 3(d)). This internal $C^{0}$ continuity always exists (Figure $4\left(\right.$ a)). For the $C^{1}$ continuity 5 d.o.f. are needed. At the two end nodes there are 4 d.o.f. $=1$ d.o.f. $(\partial w / \partial n)+3$ d.o.f. $\left(\partial w / \partial n, \partial^{2} w / \partial n \partial s, \partial^{2} w / \partial n \partial^{2} s\right)$, (Figure 3). Therefore, in general, $C^{1}$ internal continuity does not exist. However it is possible to choose the internal d.o.f. at node ' 0 ' in such a way that this $C^{1}$ continuity exists. This means that 3 conditions (one for each internal side) should be imposed, or equally 3 d.o.f. should be expressed in terms of the remaining 7, and those of the external nodes, and then eliminated at the shape function level (Figure 4(b)). This step was first made analytically, but the expression became so complicated that it was decided to use a numerical procedure.

The element stiffness matrix is obtained by the addition of the subelement stiffness matrices. Afterwards it is possible to eliminate all the remaining 7 internal d.o.f. by static condensation of the element stiffness matrix (Figure 4(c)). 


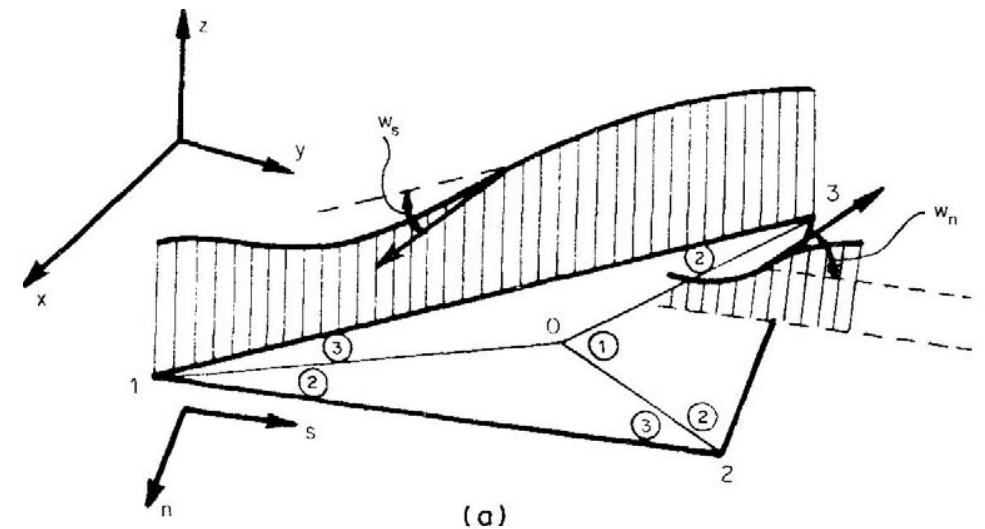

(a)

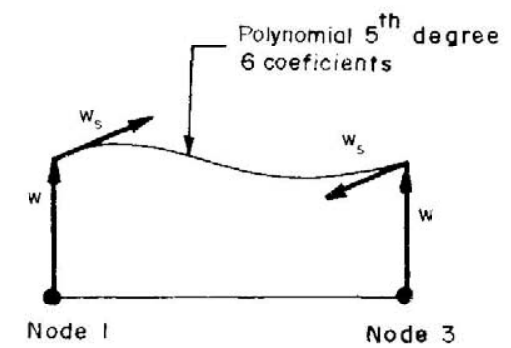

w-deflection Nodes 4 coeficients (dof) side 2 dof is needed

(b)

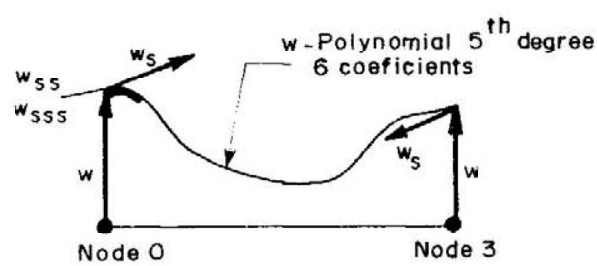

$w$ - deflection Nodes $4+2=6$ coeficients (dof) side none dof is needed

(d)

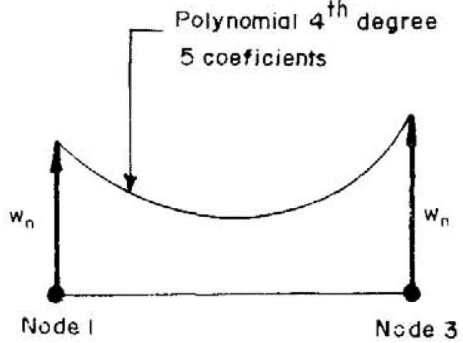

$w_{n}$-normol derivative Nodes 2 coeficients (dof) side 3 dof are needed

(c)

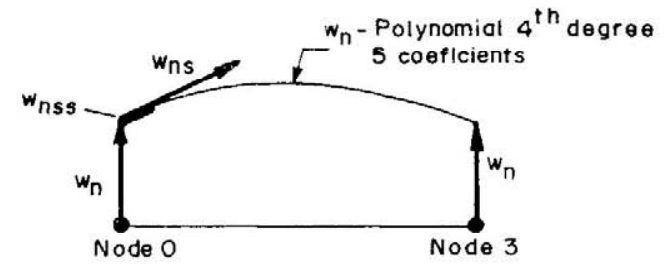

$w_{n}$ - normal derivative Nodes $3+1=4$ coeficients (dof) side I dof is needed

(e)

Figure 3. Continuity along external and internal sides: (b) $w$-deflection at the nodes -4 coefficients (d.o.f.); 2 side d.o.f. are needed; (c) $w_{n}$ - normal derivative at the nodes - 2 coefficients (d.o.f.) 3 side d.o.f. are needed; (d) $w \cdots$ deflection at the nodes $-4+2=6$ coefficients (d.o.f.); no side d.o.f. are needed; (c) $w_{n} \quad-$ normal derivative at the nodes $\cdots 3+1=4$ coefficients (d.o.f.); 1 side d.o.f. is needed

It is important to point out the fact that it is not possible to climinate more than 3 internal d.o.f. at the shape function level by imposing $C^{2}$ or higher order of continuity along the internal sides. ${ }^{15}$ This is because the element is simple and internal $C^{2}$ continuity produces the problem of the dependence among the d.o.f. owing to the unique value of $\partial^{2} w / \partial s \partial n=\partial^{2} w / \partial n \partial s$ at each vertex of the triangle. 


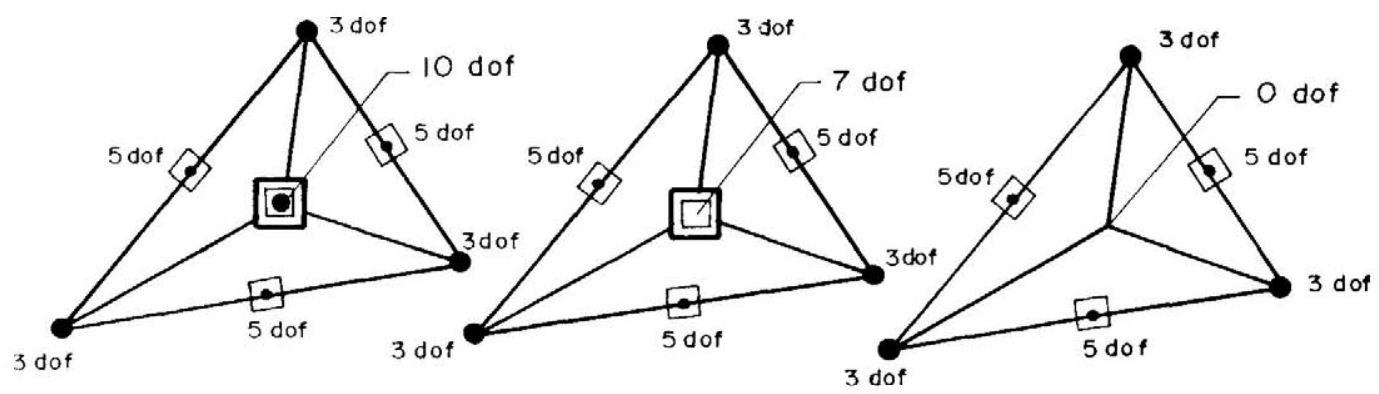

(a)

(b)

(c)

Irigure 4. Derivations of the 5 th degree element of the family: (a) element with internal continuity (" only 34 d.o.f.: (b) internal d.o.f. eliminated at shape function level: internal $C^{1}$ continuity 31 d.o.f., (c) internal d.o.f. eliminated by static condensation: internal ( ${ }^{\prime}$ continuity $2+$ d.o.f.
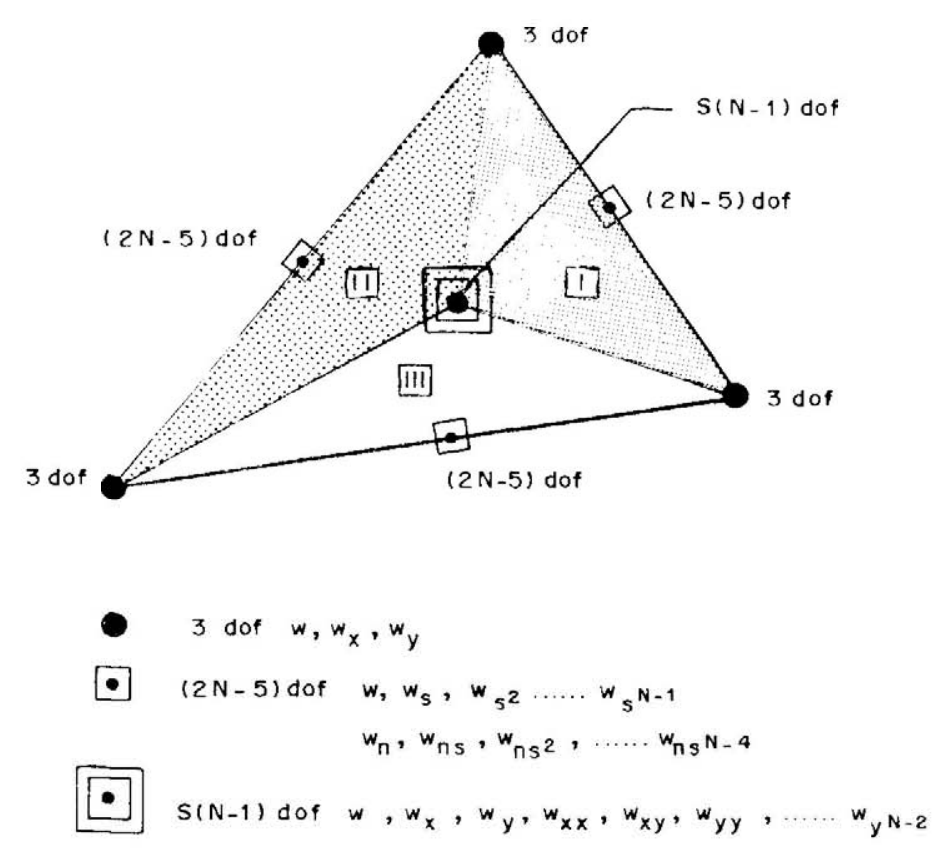

Figure 5 . A general element $N$ of the family with internal $C^{*}$ continuity only

\section{Number and distribution of d.o.f. subelement interpolation function}

The above ideas can be cxtended to a general member of the family of elements. The triangular element is divided into another three, as is depicted in Figure 5. In each of those subelements is built a complete polynomial interpolation function of degrec $N$.

The number of d.o.f. and their distribution along external and internal sides will be discussed. The total number of d.o.f. in an $N$ th degree polynomial of two variables is

$$
S(N+1)=\frac{(N+1)(N+2)}{2}
$$


where $S(N)$ is the sum of the first $N$ natural numbers.

First, along an external side the $C^{1}$ compatibility--in $w$ and $w_{n}$--implies the results of Table $\mathrm{I}$. For a polynomial of fifth degree this is explained in Figures 3(b) and 3(c).

The d.o.f. used at the central node of the external side are shown in Figure 6.

As the number of d.o.f. in the middle of an external side is $2 N-5$ (Table I) the internal d.o.f. number will be

$$
S(N+1)-2 \times 3-(2 N-5)=S(N-1)
$$

The continuity along an internal side is shown in Table II. One prescription of compatibility is imposed in order to obtain continuity in the normal derivative $\left(w_{n}\right)$ Figure $3(e)$.

The condition used here is to match the normal derivative between subelements in the middle of the internal sides, that is

$$
\begin{aligned}
& w_{n}^{\text {III }}(6)=-w_{n}^{\prime \prime}(5) \\
& w_{n}^{\prime}(6)=-w_{n}^{\prime \prime \prime}(5) \\
& w_{n}^{\prime \prime \prime}(6)=-w_{n}^{\prime \prime \prime \prime}(5)
\end{aligned}
$$

where superscripts refer to the subelements and the numbers in brackets to the nodes indicated in Figure 7.

These prescriptions could be imposed at other points and there could be more with polynomials of a higher degree than threc. It has been proved ${ }^{15}$ that it is not possible to enforec more than three

\begin{tabular}{|c|c|c|c|c|}
\hline & Function & $\frac{\mathrm{A}}{w(\text { degree } N)}$ & $\frac{\text { B }}{w_{n}(\text { degree } N-1)}$ & $\begin{array}{l}\Lambda+\mathrm{B} \\
w+w_{n}\end{array}$ \\
\hline 1 & D.O.F. for $C^{1}$ continuity & $N+1$ & $N$ & $2 N+1$ \\
\hline II & Corner d.o.f. & $2 \times 2$ & $2 \times 1$ & 6 \\
\hline $\mathrm{III}=\mathrm{I}-\mathrm{II}$ & side d.o.f. excluding the corners & $N-3$ & $N-2$ & $2 N-5$ \\
\hline
\end{tabular}
conditions between subclements. In this family of finite clements the 3 d.o.f. at the centre of gravity, chosen to be dependent, are $w, \partial w / \partial x, \partial w / \partial y$.

Table I. D.O.F. distribution on an external side

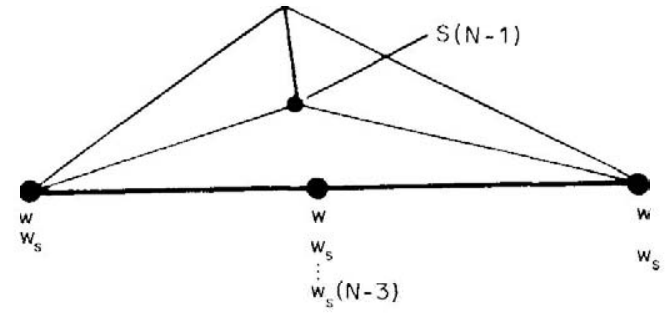

(a)

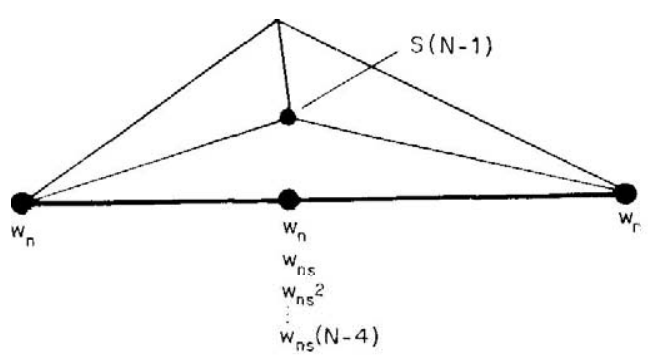

(b)

Figure 6. Continuity along an external side: (a) d.o.f. $-2+2+N-4+1=N+1$ : number of constants in a polynomial of $N$ th order $=N+1$; (b) d.o.f $=N$; number of constants in a polynomial of $(N-1)$ th order $=N$; d.o.f. at a node $=(N-4+1)+(N-3+1)=2 N-5$; d.o.f. at the centre of gravity $=S(N+1)-2 \times 3-(2 N-5)=S(N-1)$ 
Table II. D.O.F. distribution in an internal side

\begin{tabular}{ccccc}
\hline & \multicolumn{1}{c}{ Function } & $\begin{array}{c}\mathrm{A} \\
w(\mathrm{degrec} N)\end{array}$ & $\begin{array}{c}\mathrm{B} \\
w_{n}(\mathrm{degrec} N-1)\end{array}$ & $\begin{array}{c}\mathrm{A}+\mathrm{B} \\
w+w_{n}\end{array}$ \\
\hline $\mathrm{I}$ & D.O.F. for $C^{1}$ continuity & $N+1$ & $N$ & $2 N+1$ \\
\hline II & D.O.F. at an external corner & 2 & 1 & 3 \\
\hline III & D.O.F. at the centre of gravity, & $N-1$ & $N-2$ & $2 N-3$ \\
\hline IV $=$ II + III & D.O.F. on an internal side & $N+1$ & $N-1$ & $2 N$ \\
\hline
\end{tabular}

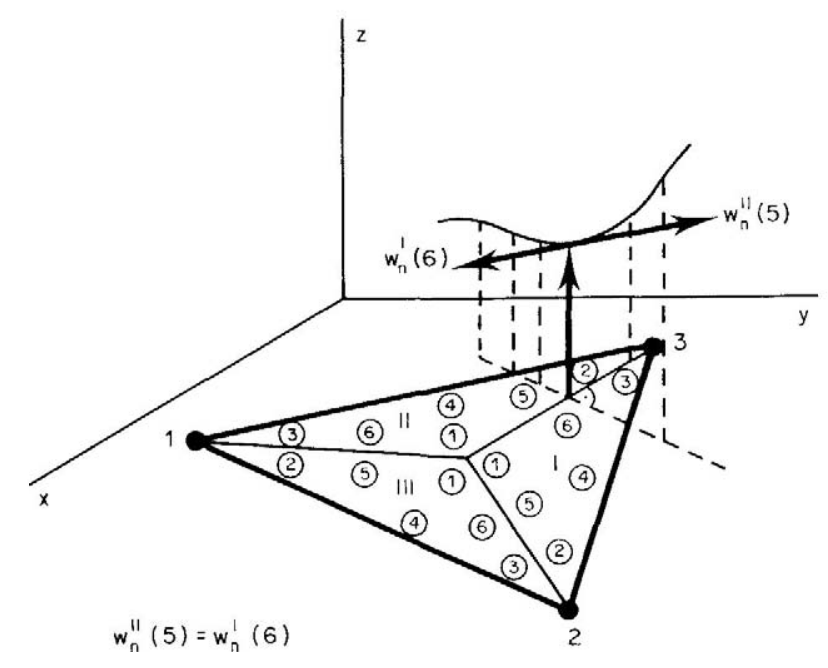

Figure 7. Internal continuity $C^{1}$

Analytical expression

As in a general F-E-M procedure, the general interpolation function is for each subelement.

$$
w^{(i)}=\mathbf{L} \boldsymbol{\alpha}^{(i)}
$$

where $i$ means the number of the subelement, $L$ is a vector of $S(N+1)$ components $L_{1}^{a}, L_{2}^{b}, L_{3}^{c}\left(L_{i}\right.$ are baricentric co-ordinates; see Figure 8 for $N=4), \alpha$ is a vector of $S(N+1)$ constants $\alpha_{a b c}$.

If $\mathbf{d}$ are the d.o.f. ( $w$ and its derivatives) it can be obtained from (3) that

$$
\mathbf{d}^{(i)}=\mathbf{C}^{(i)} \boldsymbol{\alpha}^{(i)}
$$

and hence that

$$
\boldsymbol{\alpha}^{(i)}=\overline{\mathbf{C}}^{(i)} \mathbf{d}^{(i)}
$$

Then the interpolation function expression is

$$
w^{(i)}=\mathbf{L} \bar{C}^{(i)} \mathbf{d}^{(i)}=\boldsymbol{\phi} \mathbf{d}^{(i)}=\sum_{j=1}^{S(N+1)} \phi^{j} d_{j}^{(i)}
$$

From the vectors of d.o.f. of each subelement, $\mathbf{d}^{(i)}$, another vector $\mathbf{d}^{*}$ including all of them 


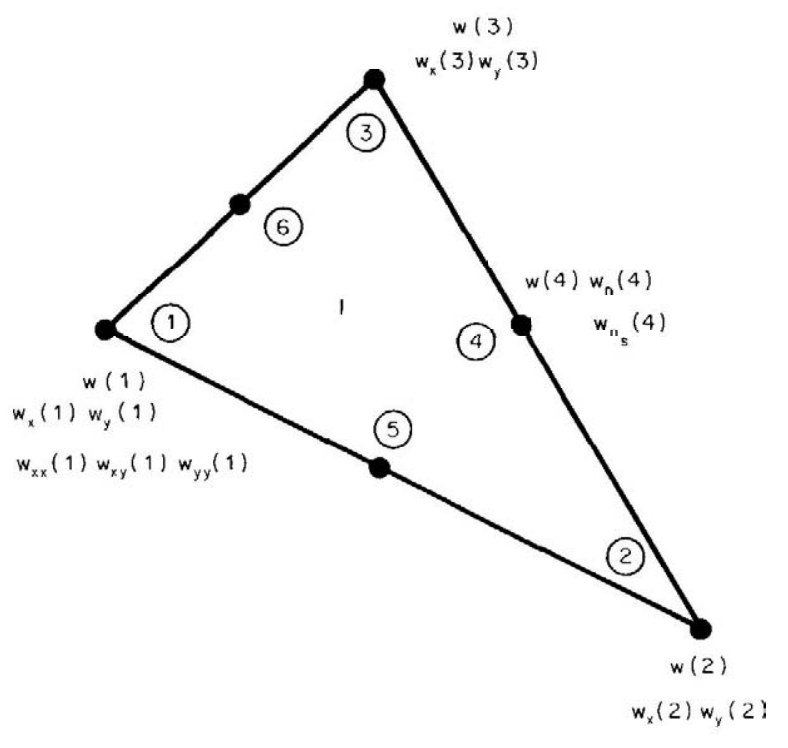

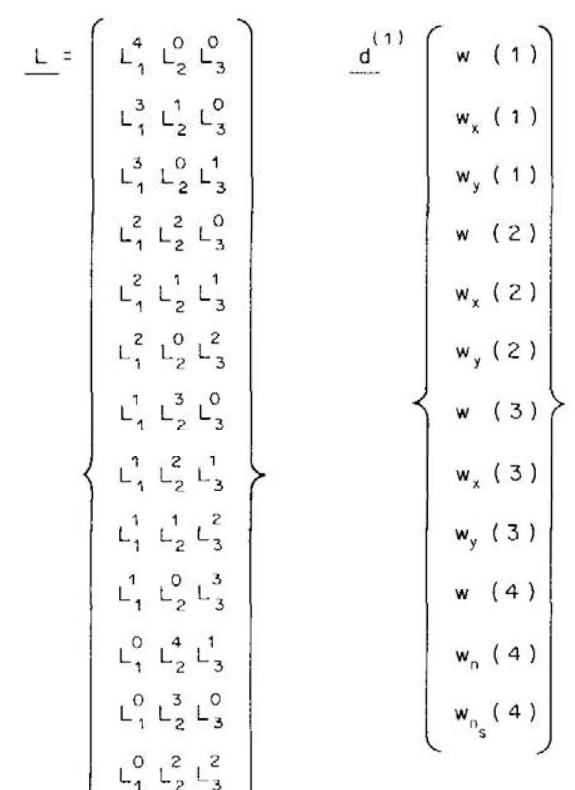

Figure 8. Baricentric interpolation coefficients for $N=4$. Vectors $\mathbf{I}$. and $\mathbf{d}^{(1)}$

$\left(\mathbf{d}^{(1)}, \mathbf{d}^{(2)}, \mathbf{d}^{(3)}\right)$ is formed, taking into account the fact that some d.o.f. are the same in different subelements. It is possible to divide $\mathbf{d}^{*}$ into two vectors $\left(\mathbf{d}_{0}^{*}, \mathbf{d}_{1}^{*}\right)^{\mathrm{T}}$, so that $\mathbf{d}_{0}^{*}$ contains the linearly dependent d.o.f. and $\mathbf{d}_{1}^{*}$ the independent, after imposing $C^{1}$ continuity.

Equation (6a) now has another form:

$$
w^{(i)}=\mathbf{L} \overline{\mathbf{C}}^{(i)} \mathbf{d}^{(i)}=\mathbf{L}\left(\overline{\mathbf{C}}_{0}^{(i)}, \overline{\mathbf{C}}^{(i)}\right)\left(\mathbf{d}_{0}^{*}, \mathbf{d}_{1}^{*}\right)^{\mathbf{T}}=\boldsymbol{\phi}^{(i) * *} \mathbf{d}^{*}=\sum_{j=1}^{M} \phi^{(i) * i} d_{j}^{*}
$$

where

$$
M=3(3+2 N-5)+S(N-1)
$$

and the equation system (2) can be expressed as

$$
\begin{aligned}
& \phi_{n}^{(3) *}(6) \mathbf{d}^{*}=-\boldsymbol{\phi}_{n}^{(1) *}(5) \mathbf{d}^{*} \\
& \phi_{n}^{(1) *}(6) \mathbf{d}^{*}=-\phi_{n}^{(2) *(5) \mathbf{d}^{*}} \\
& \phi_{n}^{(2) *}(6) \mathbf{d}^{*}=-\phi_{n}^{(3) *}(5) \mathbf{d}^{*}
\end{aligned}
$$

where

$$
w_{n}=\boldsymbol{\phi}_{n}^{(i) *} \mathbf{d}^{*}
$$

and hence

$$
\begin{gathered}
\mathbf{H}_{0} \mathbf{d}_{0}^{*}+\mathbf{H}_{1} \mathbf{d}_{1}^{*}=\mathbf{0} \\
\mathbf{d}_{0}^{*}=-\mathbf{H}_{0}^{-1} \mathbf{H}_{1} \mathbf{d}_{1}^{*}=\mathbf{H d}_{1}^{*}
\end{gathered}
$$


so that (6b) becomes

$$
w^{(i)}=\mathbf{L}\left(\overline{\mathbf{C}}_{0}^{(i)} \overline{\mathbf{C}}_{1}^{(i)}\right)\left(\mathbf{H} \mathbf{d}_{1}^{*}, \mathbf{d}_{1}^{*}\right)^{\mathbf{T}}=\mathbf{L}\left(\overline{\mathbf{C}}_{0}^{(i)} \mathbf{H}+\overline{\mathbf{C}}_{1}^{(i)}\right) \mathbf{d}_{1}^{*}=\mathbf{L} \mathbf{C} \mathbf{d}_{1}^{*}=\hat{\boldsymbol{\phi}}^{(i)} \mathbf{d}_{1}^{*}
$$

The shape function $\hat{\phi}^{i}$ corresponding to the displacement $w$ at node 3 in a subelement for several degrees of polynomials is given in Figure 9.

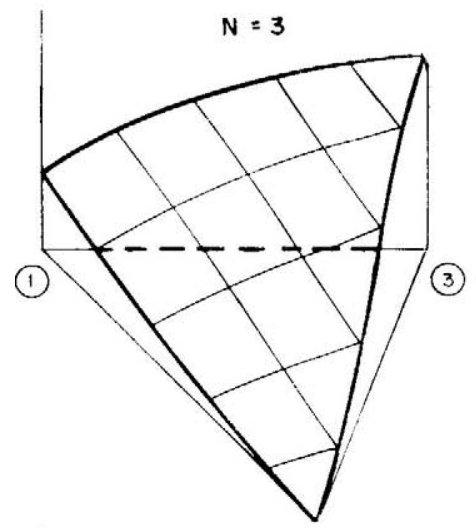

(2)

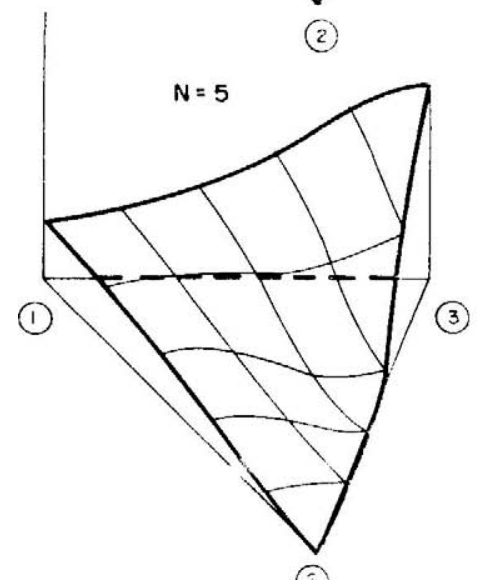

(2)

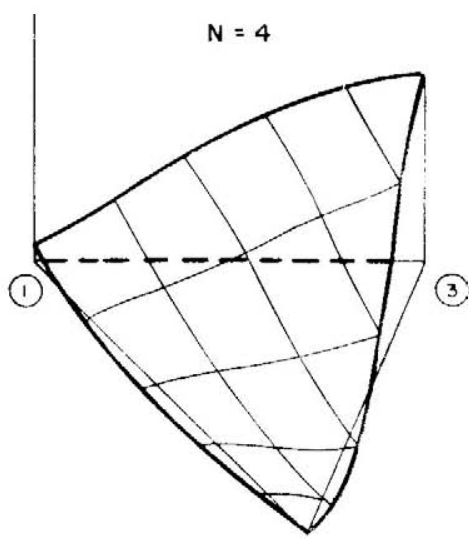

(2)

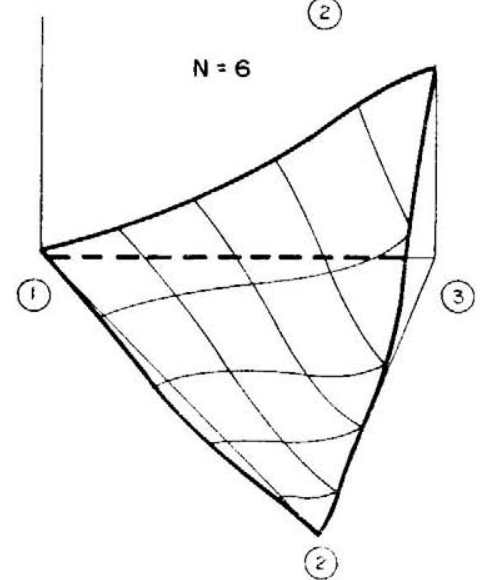

(2)

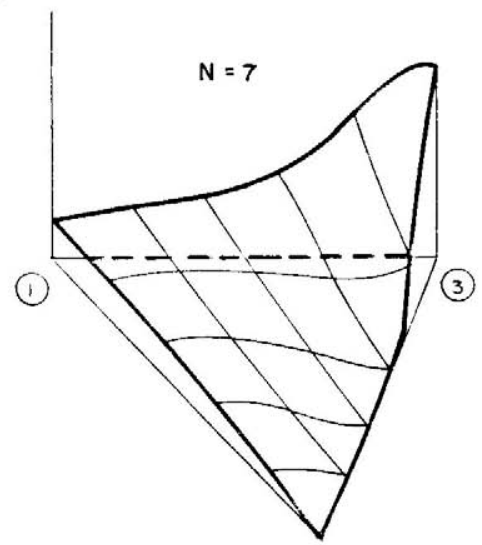

(2)

Figure 9. Deflection shape function $\phi^{(i)}$ at node 3 of a subelement 
In Figure 10 the first three elements of the family are depicted.

Element stiffness matrix, static condensation and structural assembly

Using the plate governing equations and equations (9) the element stiffness matrix and equivalent forces are obtained. Owing to the fact that the internal node is not needed, the d.o.f. that are there can be eliminated by static condensation.

Afterwards the element stiffness matrices are added to generate the total stiffness matrix for the plate structure and in a similar way the complete equivalent force vector

$$
\mathbf{P}=\mathbf{K d}
$$

where

$$
\begin{aligned}
& \mathbf{K}=\sum_{i=1}^{n} \iint_{A_{i}}\left(\mathbf{B}^{i}\right)^{\mathrm{T}} \mathbf{D} \mathbf{B}^{i} \mathrm{~d} A \\
& \mathbf{P}=\sum_{i=1}^{n}\left\{\iint_{A_{i}}\left\{\left(\mathbf{B}^{i}\right)^{\mathrm{T}} \mathbf{D} \varepsilon_{O}^{i}+\left(\psi^{i}\right)^{\mathrm{T}} \mathbf{b}+\left(\psi^{i}\right)^{\mathrm{T}} \mathbf{P}\right\} \mathrm{d} A_{i}+\int_{\mathcal{A} \wedge A,_{A}}\left(\psi^{i \mathrm{~T}}\right) \mathbf{P s} \mathrm{d} s\right\}
\end{aligned}
$$

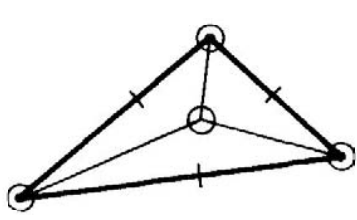

$N=3$

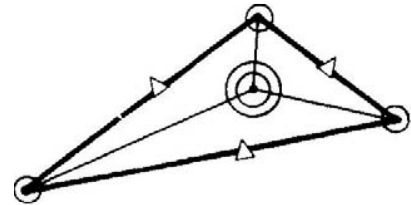

$N=4$

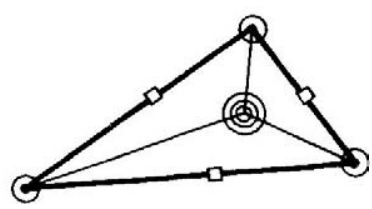

$N=5$

$$
\begin{aligned}
& n_{1}=15 \\
& n_{2}=12
\end{aligned}
$$$$
n_{1}=24
$$$$
n_{1}=34
$$$$
n_{2}=21
$$$$
n_{2}=31
$$

$$
\begin{aligned}
& \text { (2) } w_{,}, w_{x}, w_{y}, w_{y}, w_{x x}, w_{x y}, w_{y y} \\
& \text { (9, } w_{x}, w_{y}, w_{x x}, w_{x y}, w_{y y}, w_{x x x}, w_{x x y}, w_{x y y}, w_{y y y} \\
& \Delta w_{n} \\
& \square w_{n} w_{n s} / w \\
& n_{1}=w_{n} w_{n_{s}} w_{n_{s s}} / w w_{s} \\
& n_{2}=\text { dof number without internal compotibility }
\end{aligned}
$$

Figure 10. The first three elements of the family 

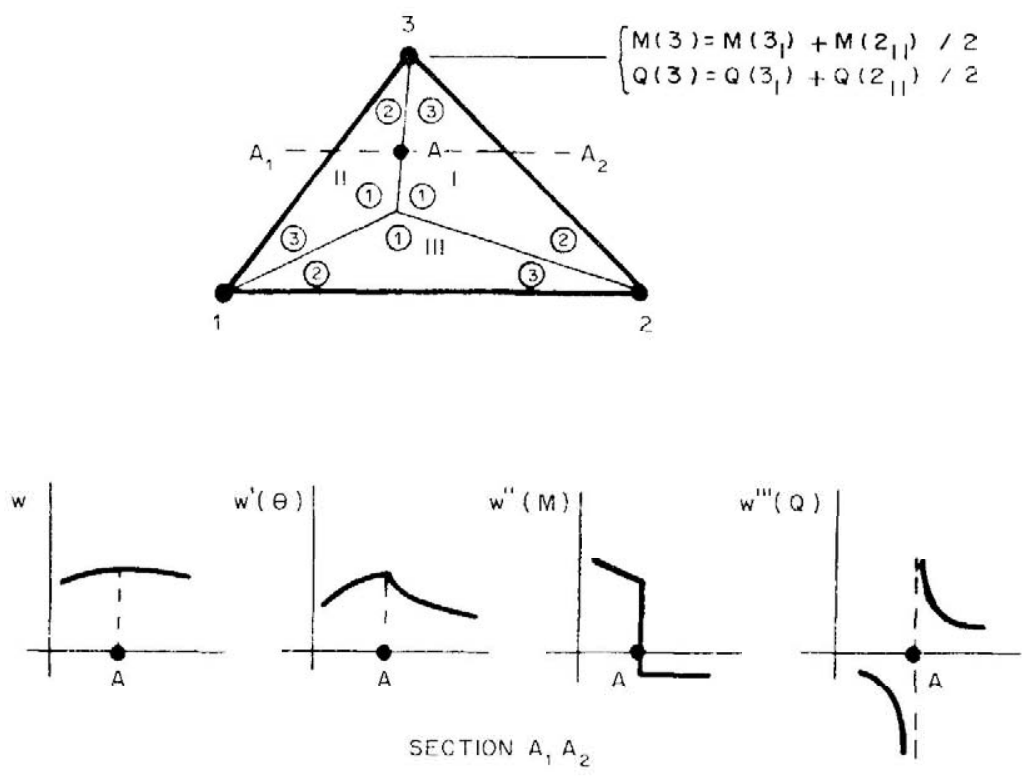

Figure 11. Evaluation of the results

\section{Results}

As there are three subtriangles in each subelement, there are three groups of shape functions as well. There are no problems in deflection $(w)$ and its first-order derivatives on the frontier between subelements, so that $C^{1}$ continuity exists. In the second-and third-order derivatives, that represent the bending moment and the shear force, there is no continuity. Thus the average of the subelement results has been made (Figure 11 ).

The element stiffness matrix has been used as well in order to obtain the results. The accuracy is improved, especially in the shear force.

\section{NUMERICAL RESULTS}

\section{Numerical results}

The elements of this family have been applied to numerous cases in order to know their performance in relation to several variables: influence of the load type, boundary conditions, skewness of the elements, relation between the lengths of the sides and mesh patterns.

Loading and boundary conditions. As an example a typical case is tested: a square plate of side $a$ with Poisson's ratio equal to $0 \cdot 3$. Two cases are presented: a built-in plate along the boundary with a uniform load of intensity $q$ (Table III), and a plate, supported simply by its corners under a point load $P$ at the centre (Table IV).

Skewness. In order to check the performance of these elements with irregular geometry for the analysis of skew plates under uniform loading with two of the opposite edges simply supported and the other two free, three different kinds of examples have been examined. In order to avoid a large computational effort the experimentation was carried out with only four clements and poly- 
Table III. Square plate: boundary built-in

Mesh type:

a: side length

a: uniform load intensity

i. 0.3 (Poisson's ratio)

w: centre deflection

$M$ : centre moment

$M_{1}, M_{2}$ : centre side moments

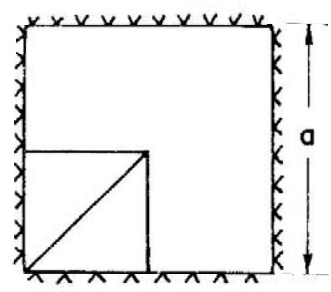

$Q$ : middle side shear

$R$ : middle side Kirchhoff reactions

DOF1: total number of d.o.f.

DOF2: number of active d.o.f.

NDEG: polynomial degree

\begin{tabular}{|c|c|c|c|c|c|c|c|c|}
\hline NDEG & $\mathrm{DOF}$ & $\mathrm{DOH} 2$ & $w$ & $M$ & $M_{1}$ & $M_{2}$ & $Q$ & $R$ \\
\hline 3 & 17 & 2 & $0 \cdot 0005422$ & $0 \cdot 01480$ & $-0 \cdot(003904$ & $-0 \cdot 01301$ & 0.05205 & $0 \cdot() 4750$ \\
\hline 4 & 27 & 6 & $0 \cdot 0012921$ & $0 \cdot 03343$ & $-0 \cdot 01123$ & $-0 \cdot 03744$ & $0 \cdot 2221$ & $0 \cdot 2302$ \\
\hline 5 & 37 & 10 & 0.001265 & $0 \cdot 02466$ & -0.01511 & $-0 \cdot 05038$ & 0.4319 & 0.4540 \\
\hline$\cdots$ & & & & & & & & (") \\
\hline 6 & 47 & 14 & $0 \cdot(001263$ & ()$\cdot() 2056$ & $-(0 \cdot() 1547$ & $-0 \cdot 05156$ & 0.4515 & $(0.4714$ \\
\hline 7 & 57 & 18 & $0 \cdot 001266$ & 0.02410 & $-0 \cdot 01546$ & $-0 \cdot 05152$ & $(0 \cdot 4545$ & 0.4672 \\
\hline Exact $^{16}$ & & & $0 \cdot 00126$ & $0 \cdot(0231$ & $-0 \cdot 01540$ & $-0 \cdot 0513$ & $0 \cdot 4405^{17}$ & $0.4403^{17}$ \\
\hline Cocfficient & & & $4 a^{4} / D$ & $q a^{2}$ & $4 a^{2}$ & $q a^{2}$ & $q a$ & $4 a$ \\
\hline
\end{tabular}

Table IV. Square plate: simply supported corners Mesh type:

a: side length

$P$ : centre point load intensity

v: $0 \cdot 3$ (Poisson's ratio)

w: centre deflection

$w_{1}$ : centre side deflection

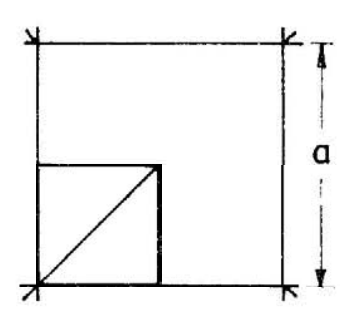

$M$ : centre moment

$R_{\mathrm{c}}$ : corner reaction

DOF1: total number of d.o.f

DOF2: number of active d.o.f.

NDEG: polynomial degree

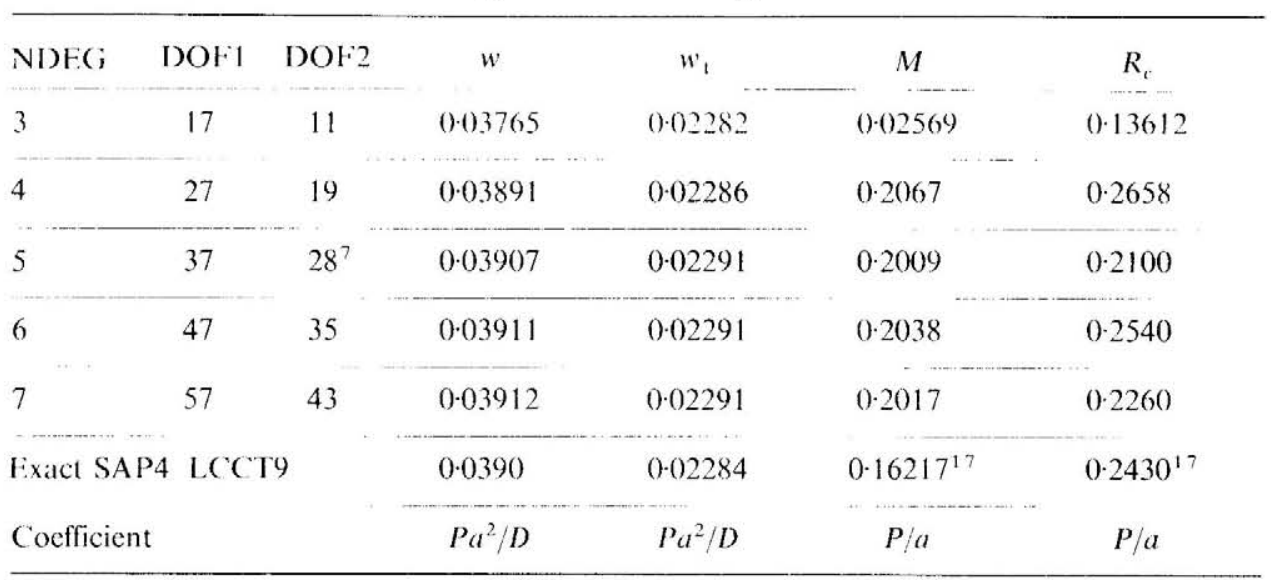


Mesh type:

$b$ : simply supported side c: free side

h, $c$ : sides lengths

4: uniform load intensity

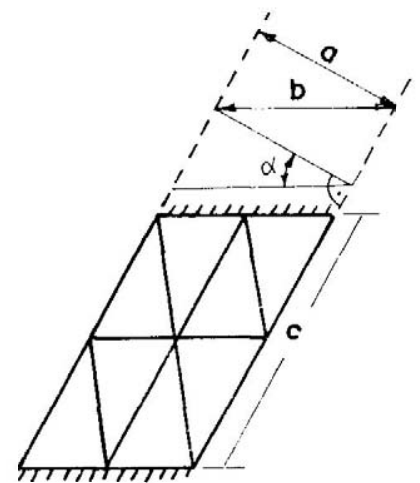

v: $0 \cdot 3$ (Poisson's ratio)

$w$ : centre deflection

$M$ : centre moment

DOF1: total number of d.o.f.

DOF2: number of active d.o.f.

NDEG: polynomial degree.

\begin{tabular}{|c|c|c|c|c|c|c|c|c|}
\hline \multirow[b]{2}{*}{ NDEG } & \multirow[b]{2}{*}{ DOF 1} & \multirow[b]{2}{*}{ DOF 2} & $\alpha=30$ & $\begin{array}{l}b=1.5 a \\
c=1.9245 a\end{array}$ & $\alpha=45$ & $\begin{array}{l}b=1.41 a \\
c=2 a\end{array}$ & $\alpha=60$ & $\begin{array}{l}b=2 a \\
c=2 a\end{array}$ \\
\hline & & & $w$ & $M$ & $w$ & $M$ & $w$ & $M$ \\
\hline 3 & 43 & 31 & $0 \cdot 1045$ & 0.46850 & 0.06642 & 0.29507 & $0 \cdot 01487$ & 0.12848 \\
\hline 4 & 75 & 59 & $0 \cdot 1052$ & 0.46789 & 0.06935 & $0 \cdot 31064$ & 0.01742 & $0 \cdot 16652$ \\
\hline Exact $^{18}$ & & & 0.1183 & 0.368 & 0.07080 & 0.291 & 0.01860 & $0 \cdot 1660$ \\
\hline Coeffici & & & $q a^{4} / D$ & $q a^{2}$ & $q a^{4} / D$ & $q a^{2}$ & $q a^{4} / D$ & $q a$ \\
\hline
\end{tabular}

nomials of degree no higher than the fourth. The accuracy obtained in the results can only indicate the tendency. The results are shown in Table V.

Different side relationships. The influence of the ratio between the lengths of the sides is shown in Table VI for a simply supported rectangular plate with uniform load.

Mesh dependence. The importance of the type of mesh pattern is depicted in Figure 12 for a square built-in plate under uniform loading. The best results are obtained from the $\mathrm{C}$ mesh type, especially $1 \mathrm{C}$ and $2 \mathrm{CE}$. Similar results could be shown for a simply supported square plate under point loading. In any case the monotonous convergence is ensured because the elements are $C^{1}$.

\section{Comparative study with other elements}

In order to assess not only the speed of convergence of this family of the elements but its possible computational efficiency as well, a comparative study with other clements is carricd out. The comparative variable is the number of d.o.f.; however it does not represent the total computational effort, because in high-order polynomials the generation of the stiffness matrix demands considerable computer time.

The results are depicted in Figures 13 and 14. They are related only to bending moment and central deflection. The results for the shear force are not normally published since their error rate is usually fairly high. However the results obtained with this family are quite accurate even for the shear force. 
Table VI. Rectangular plate: boundary simply supported

Mesh type:

$a, b$ : side lengths

$q$ : uniform load intensity

v: $0 \cdot 3$ (Poisson's ratio)

w: centre deflection

$M_{1} M_{2}$ : centre moments

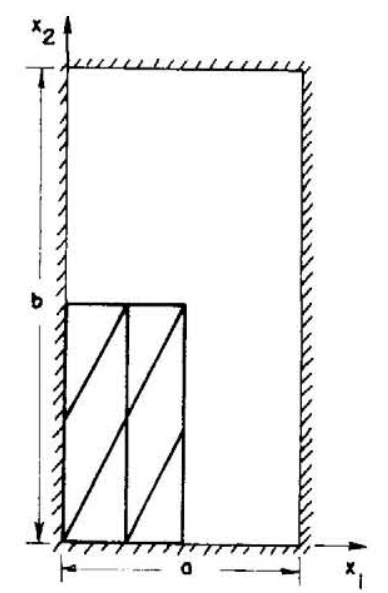

$Q_{1} Q_{2}:$ centre side shear

$R_{1} R_{2}$ : centre side Kirchhoff reactions

DOF1: total number of d.o.f.

DOF2 : number of active d.o.f.

NDEG: polynomial degree

\begin{tabular}{|c|c|c|c|c|c|c|c|c|c|c|}
\hline$b / a$ & NDEG & DOF1 & DOF2 & $w$ & $M_{1}$ & $M_{2}$ & $Q_{1}$ & $Q_{2}$ & $R_{1}$ & $R_{2}$ \\
\hline \multirow{3}{*}{1.5} & 3 & 43 & 24 & 0.007594 & 0.07633 & 0.04223 & $0 \cdot 2293$ & $0 \cdot 1485$ & $0 \cdot 2808$ & $0 \cdot 2419$ \\
\hline & 4 & 75 & 48 & 0.007724 & 0.08101 & 0.04989 & $0 \cdot 4485$ & $0 \cdot 3477$ & 0.5196 & 0.4764 \\
\hline & Exact $^{19}$ & & & 0.00772 & 0.0812 & 0.0498 & 0.424 & $0 \cdot 363$ & 0.486 & 0.480 \\
\hline \multirow{3}{*}{$2 \cdot 0$} & 3 & 43 & 24 & 0.009996 & 0.09480 & 0.03940 & 0.2841 & $0 \cdot 1295$ & $0 \cdot 3200$ & $0 \cdot 2268$ \\
\hline & 4 & 75 & 48 & 0.01013 & $0 \cdot 1016$ & 0.04651 & $0 \cdot 4990$ & $0 \cdot 3249$ & 0.5426 & 0.4666 \\
\hline & Exact $^{19}$ & & & 0.01013 & $0 \cdot 1017$ & 0.0464 & 0.465 & $0 \cdot 370$ & 0.503 & 0.496 \\
\hline \multirow{4}{*}{$3 \cdot 0$} & 3 & 43 & 24 & 0.01221 & 0.1163 & 0.03757 & 0.3519 & $0 \cdot 1006$ & $0 \cdot 3681$ & 0.1852 \\
\hline & 4 & 75 & 48 & 0.01223 & 0.1189 & $0 \cdot 04071$ & 0.5346 & $0 \cdot 2618$ & 0.5469 & 0.4083 \\
\hline & Exact $^{19}$ & & & 0.01223 & 0.1189 & 0.0406 & 0.493 & 0.372 & 0.505 & 0.498 \\
\hline & Coefficie & & & $q a^{4} / D$ & $q a^{2}$ & $q a^{2}$ & $q a$ & $q a$ & $q a$ & $q a$ \\
\hline
\end{tabular}




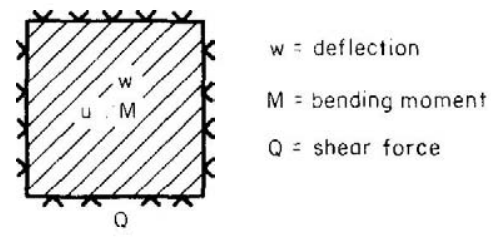

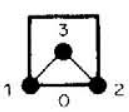
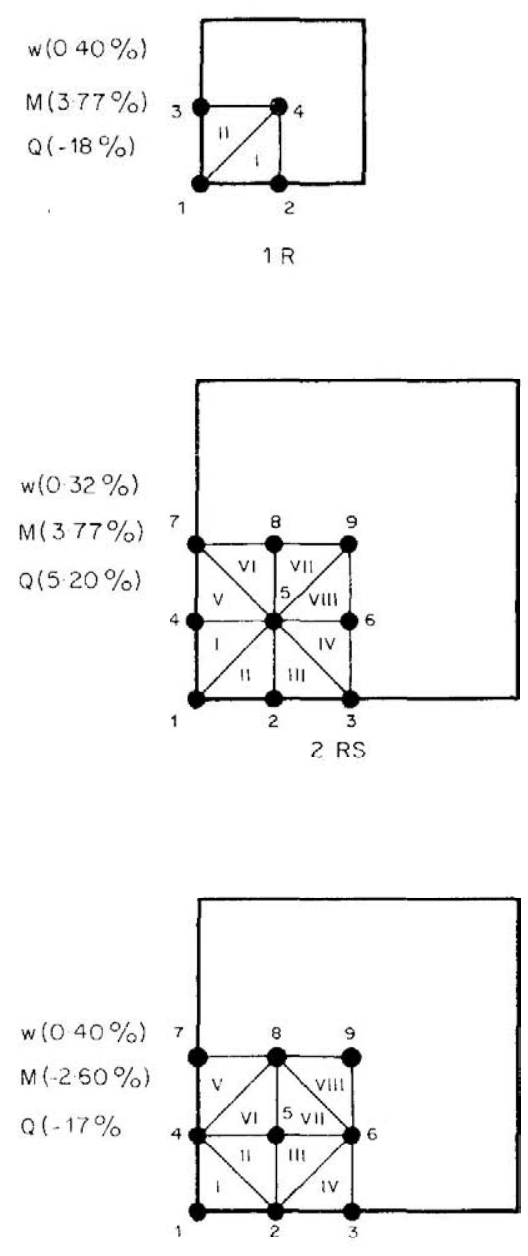

$2 \mathrm{CS}$
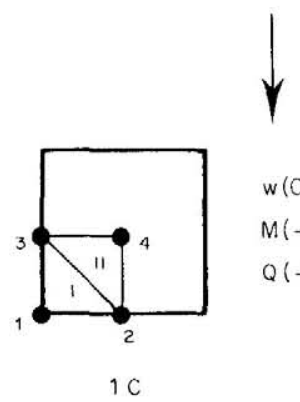

$w(0.40 \%)$ M( $-1.00 \%$ $Q(-1.98 \%)$

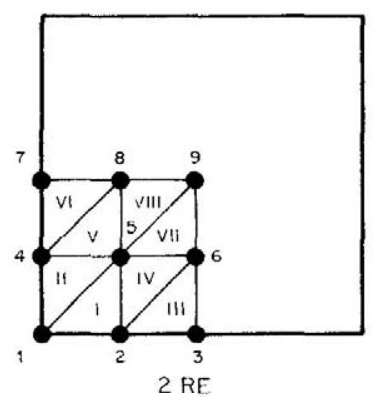

w $(0.40 \%)$

M(3.77\%)

Q $(-18 \%)$

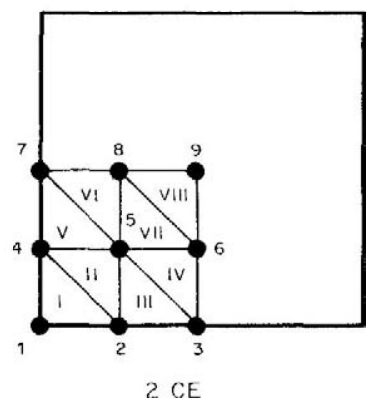

$\downarrow$

w $(0.32 \%)$ $M(-1.82 \%)$ $\mathrm{Q}(3.81 \%)$

Figure 12. Mesh types 


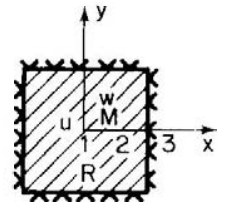

Deflection $0.5 \%$

Bending moment $4.4 \%$

Kirchoff force $6.2 \%$

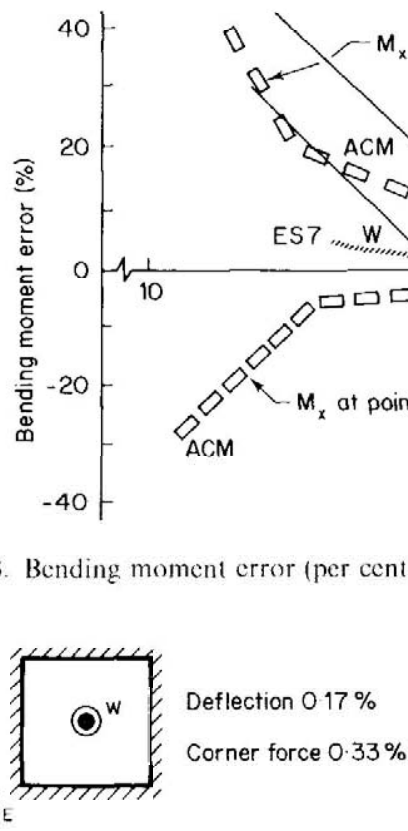

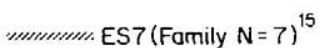

T 1 (Diaz del Valle and Samartin) $)^{17}$

- $W$ (Wegmuller) $^{20}$

$\square \square \square A C M$ (Adini, Clough)

Figure 13. Bending moment error (per cent) versus number of d.o.f. for a built-in square plate under uniform load

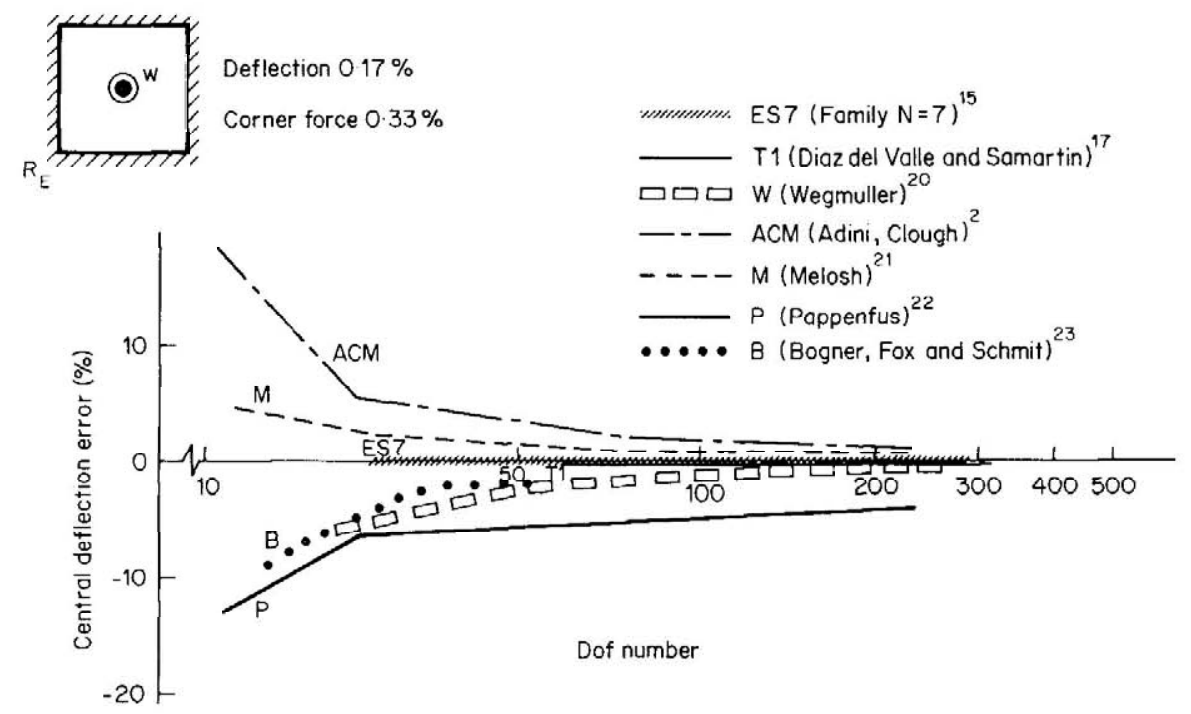

Figure 14. (entral deflection error (per cent) versus number of d.o.f. for the simply supported square plate under point-loading at the centre

\section{APPLICATIONS AND CONCLUSIONS}

With this family it is possible to reach convergence in two different ways, first by refinement of the mesh ( $h$-convergence) as in any other case, and secondly by an increase in the order of the interpolation polynomial in the element $\left(h^{k}\right.$-convergence). It has been shown above that the latter seems to be more efficient. This holds particularly if the clements are equally repeated throughout 
the domain, because the effort to obtain its stiffness matrices is drastically reduced if they are computed only once.

In comparison with hyperelements, this family has the advantage that the sharp jumps in elastic or thickness characteristics can be easily considered. However the accuracy in the results, which imply higher derivatives, is better in hyperelements because they are the d.o.f. Even though it is possible to have the dual results (high order derivatives) of the d.o.f. by using the stiffness matrix.

The results have been obtained with polynomials between the third and seventh degrees and using numerical integration. It has been observed that high order derivatives present a great sensitivity and numerical noise may appear.

It is also very easy to use this family in shells as the high order derivatives have direct compatibility. ${ }^{11}$

\section{POSSIBLE EXTENSIONS}

Some practical tables for special boundary conditions, changing of thickness, and elastic constants are to be made with the use of these elements.

The intersubelement continuity achieved is $C^{1}$. The possible maximum is still open to study. ${ }^{24}$ The analysis of the influence of the choice of d.o.f. to be eliminated at the centre node in order to obtain the internal continuity is to be carried out.

The noise produced in high order derivatives is to be assessed, especially for the matrix conditioning.

The results for the variables that are not d.o.f. can be obtained (a) by using shape functions at the point, (b) by using the shape functions and their values at the integration points, (c) by means of the stiffness matrix for the dual variables of the d.o.f. A comparison between these three methods would be of great interest. ${ }^{9}$ Some results of the third method have shown a very good accuracy.

The extension to curved compact supports would be very useful for the case of irregular boundaries.

The extensive numerical experimentation has been carricd out only with polynomials of degree less than seven because the integration tables for triangles are not a vailable for higher degrees. The extension of these tables to higher degree polynomials would be very interesting.

The use of several kinds of elements within the family can relieve some computational effort. Low degrec elements can be used near the boundary, normally in large numbers in order to model the geometry, and only a few high degree clements are usually required in the central area of the plate. Obviously the hierarchic family should include transitional clements. These can be obtained either directly or from a normal element by reduction of the order along some sides of the element.

In order to allow the simultaneous use of elements of different orders, the introduction of a general nomenclature in the hierarchic families may be useful.

\section{ACKNOWLFDGEMENTS}

The authors wish to acknowledge the comments of the reviewers that have helped to improve the clarity of this paper.

\section{APPENDIX}

\section{Triangles formulation}

The values shown in Figure 15, considering cyclic permutation $(i=1,2,3, j=2,3,1, k=3,1,2$, , are as follows 


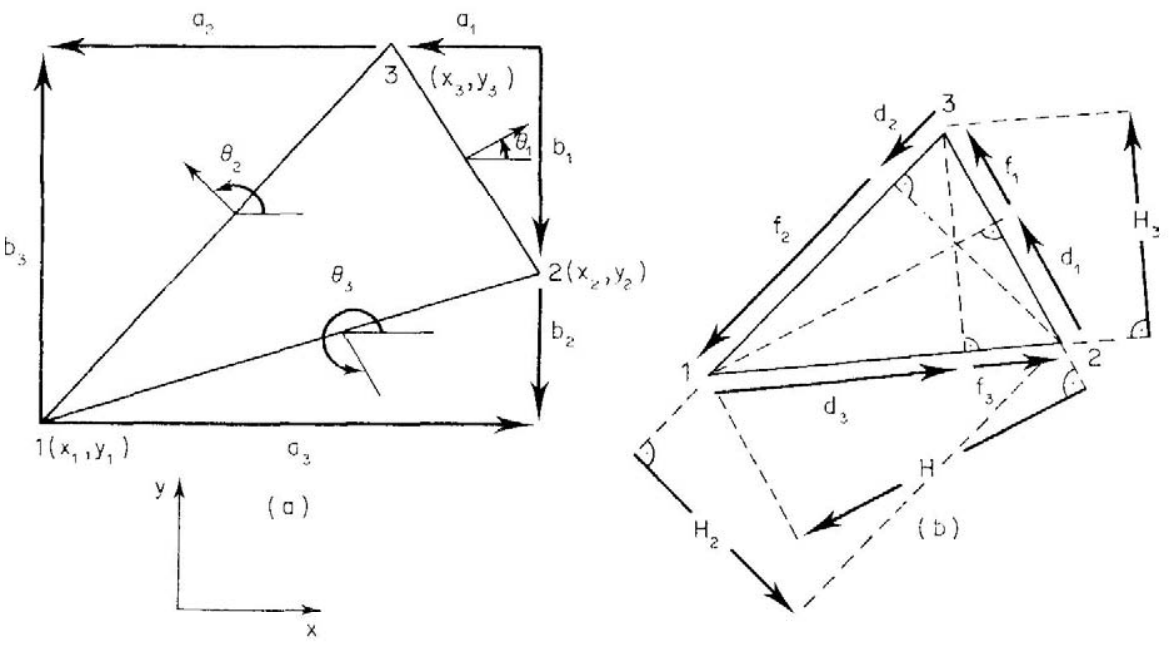

Figure 15. Triangle parameters

$$
\begin{aligned}
& a_{i}=x_{k}-x_{j} \\
& b_{i}=y_{j}-y_{k}
\end{aligned}
$$

with

$$
\begin{aligned}
\sum_{i=1}^{3} a_{i} & =\sum_{i=1}^{3} b_{i}=0 \\
a_{i} & =-\left(a_{j}+a_{k}\right) \\
b_{i} & =-\left(b_{j}+b_{k}\right) \\
d_{i} & =a_{k} \sin \theta_{i}+b_{k} \cos \theta_{i}=\frac{a_{i} a_{k}+b_{i} b_{k}}{e_{i}} \\
e_{i} & =a_{i} \sin \theta_{i}+b_{i} \cos \theta_{i}=\sqrt{\left(a_{i}^{2}+b_{i}^{2}\right)} \\
f_{i} & =a_{j} \sin \theta_{i}+b_{j} \cos \theta_{i}=\frac{a_{i} a_{j}+b_{i} b_{j}}{e_{i}} \\
H_{i} & =a_{k} \cos \theta_{i}-b_{k} \sin \theta_{i}=\frac{a_{i} b_{j}-b_{i} a_{j}}{e_{i}} \\
-H_{i} & =a_{j} \cos \theta_{i}-b_{j} \sin \theta_{i}=\frac{a_{i} b_{k}-b_{i} a_{k}}{e_{i}}
\end{aligned}
$$

where

$$
d_{i}+f_{i}+e_{i}=0
$$

The triangle area and intrinsic co-cordinates are (for $i=1,2,3$ )

$$
\begin{aligned}
2 A & =a_{i} b_{k}-b_{i} a_{k}=-\left(a_{i} b_{j}-b_{i} a_{j}\right) \\
\lambda_{i} & =\frac{d_{i}}{-e_{i}}
\end{aligned}
$$




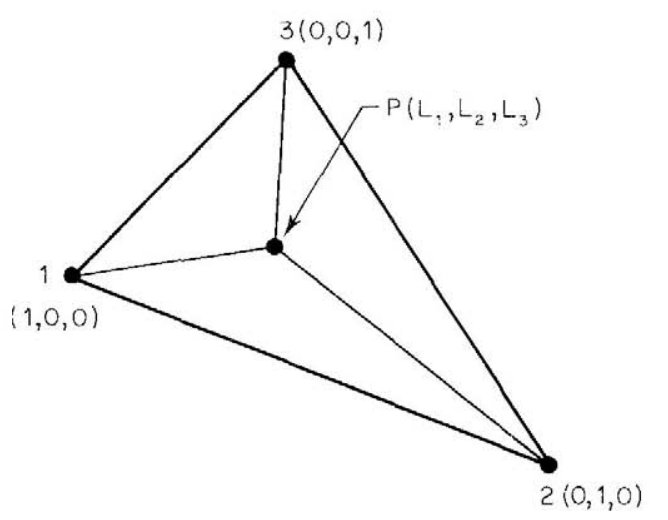

$L_{1}=\frac{\text { Areo } \widehat{P 23}}{\widehat{\text { Area }}}=\frac{h_{123}}{H_{1}}$

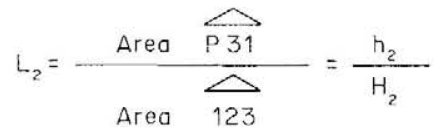

$L_{3}=\frac{\text { Area } \frac{\widehat{P 12}}{\widehat{A r e a}}}{\widehat{123}}=\frac{h_{3}}{H_{3}}$

Figurc 16. Triangular co-ordinates

$$
\mu_{i}=1-\hat{\lambda}_{i}=\frac{d_{i}}{-e_{i}}
$$

The relationship between the triangular and Cartesian co-ordinate systems (Figure 16) is as follows:

$$
\left[\begin{array}{l}
L_{1} \\
L_{2} \\
L_{3}
\end{array}\right]=\frac{1}{2 A}\left[\begin{array}{lll}
2 A_{23} & b_{1} & a_{1} \\
2 A_{31} & b_{2} & a_{2} \\
2 A_{12} & b_{3} & a_{3}
\end{array}\right]\left[\begin{array}{l}
1 \\
x \\
y
\end{array}\right]
$$

where

$$
2 A_{i j}=x_{i} y_{j}-x_{j} y_{i}
$$

and the inverse transformation is

$$
\left[\begin{array}{l}
1 \\
x \\
y
\end{array}\right]=\left[\begin{array}{lll}
1 & 1 & 1 \\
x_{1} & x_{2} & x_{3} \\
y_{1} & y_{2} & y_{3}
\end{array}\right]\left[\begin{array}{l}
L_{1} \\
L_{2} \\
L_{3}
\end{array}\right]
$$


The relationship between general and side Cartesian co-ordinates (Figure 17) is

$$
\begin{aligned}
& {\left[\begin{array}{l}
n_{i} \\
s_{i}
\end{array}\right]=\frac{1}{e_{i}}\left[\begin{array}{cc}
+b_{i} & a_{i} \\
-a_{i} & b_{i}
\end{array}\right]\left[\begin{array}{c}
x-x_{j} \\
y-y_{j}
\end{array}\right]} \\
& {\left[\begin{array}{l}
x \\
y
\end{array}\right]=\frac{1}{e_{i}}\left[\begin{array}{cc}
b_{i} & -a_{i} \\
a_{i} & b_{i}
\end{array}\right]\left[\begin{array}{cc}
n_{i} & x_{j} \\
s_{i} & y_{j}
\end{array}\right]}
\end{aligned}
$$

Following Figure 18, side Cartesian co-ordinates and triangular co-ordinates are related by

$$
\begin{aligned}
& {\left[\begin{array}{c}
n_{i} \\
s_{i} \\
1
\end{array}\right]=\left[\begin{array}{ccc}
-H_{i} & 0 & 0 \\
d_{i} & -e_{i} & 0 \\
1 & 1 & 1
\end{array}\right]\left[\begin{array}{l}
L_{i} \\
L_{k} \\
L_{j}
\end{array}\right]} \\
& {\left[\begin{array}{c}
L_{i} \\
L_{k} \\
L_{j}
\end{array}\right]=\frac{1}{2 A}\left[\begin{array}{ccc}
e_{i} & 0 & 0 \\
d_{i} & H_{i} & 0 \\
f_{i} & -H_{i} & 2 A
\end{array}\right]\left[\begin{array}{c}
n_{i} \\
s_{i} \\
1
\end{array}\right]}
\end{aligned}
$$

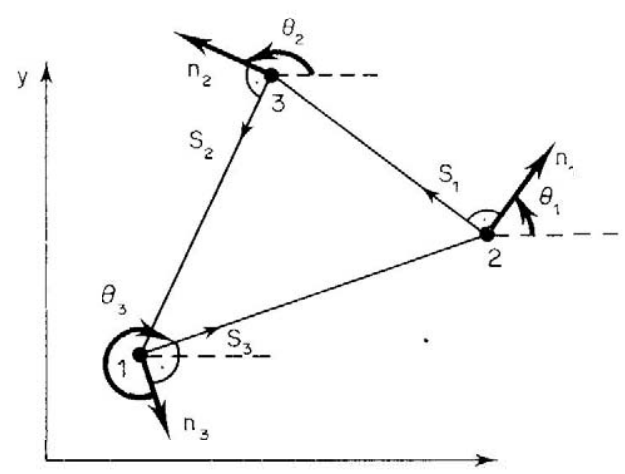

Figure 17. Side Cartesian co-ordinates

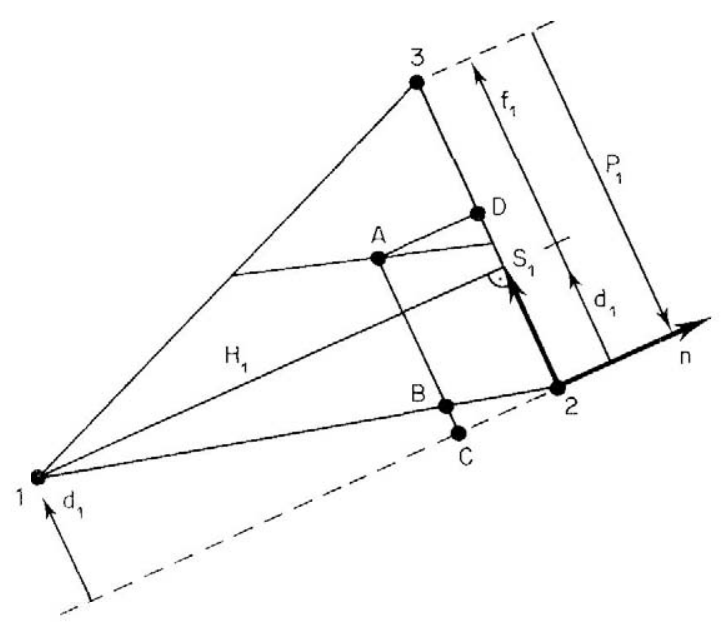

$$
\begin{aligned}
& n_{1}=|\overline{A D}| \\
& S_{1}=|\overline{A B}|+|\overline{B C}| \\
& |\overline{A D}|=H_{1} L_{1} \\
& |\overline{A B}|=-e_{1} L_{3} \\
& |\overline{B C}|=d_{1} L_{1}
\end{aligned}
$$

Figure 18 
The interco-ordinate derivatives are

$$
\begin{array}{ll}
\frac{\partial L_{i}}{\partial x}=\frac{b_{i}}{2 A}, & \frac{\partial L_{i}}{\partial y}=\begin{array}{c}
a_{i} \\
2 A
\end{array} \\
\frac{\partial L_{i}}{\partial n_{i}}=\frac{e_{i}}{2 A}, & \frac{\partial L_{i}}{\partial s_{i}}=0 \\
\frac{\partial L_{j}}{\partial n_{i}}=\frac{f_{i}}{2 A}, & \frac{\partial L_{j}}{\partial s_{j}}=\frac{-H_{i}}{2 A} \\
\frac{\partial L_{k}}{\partial n_{i}}=\frac{d_{i}}{2 A}, & \frac{\partial L_{k}}{\partial s_{i}}=\frac{H_{i}}{2 \mathrm{~A}}
\end{array}
$$

The parameters and triangular co-ordinates of subelements and the complete element are related as follows (Figure 19, in which centre number 3 is the baricentre):

$$
\begin{aligned}
& a_{1}^{(i)}=-a_{2}^{(j)}=x_{k}=-x_{i}+a_{j} \\
& a_{2}^{(i)}=-a_{1}^{(k)}=+x_{j}=x_{i}+a_{k} \\
& a_{3}^{(i)}=a_{i} \\
& h_{1}^{(i)}=-b_{2}^{(j)}=y_{k}=y_{i}+b_{j} \\
& b_{2}^{(i)}=-b_{1}^{(k)}=-y_{j}=-y_{i}+b_{k} \\
& b_{3}^{(i)}=b^{i}
\end{aligned}
$$

As the node 3 of each subelement is the baricentre:

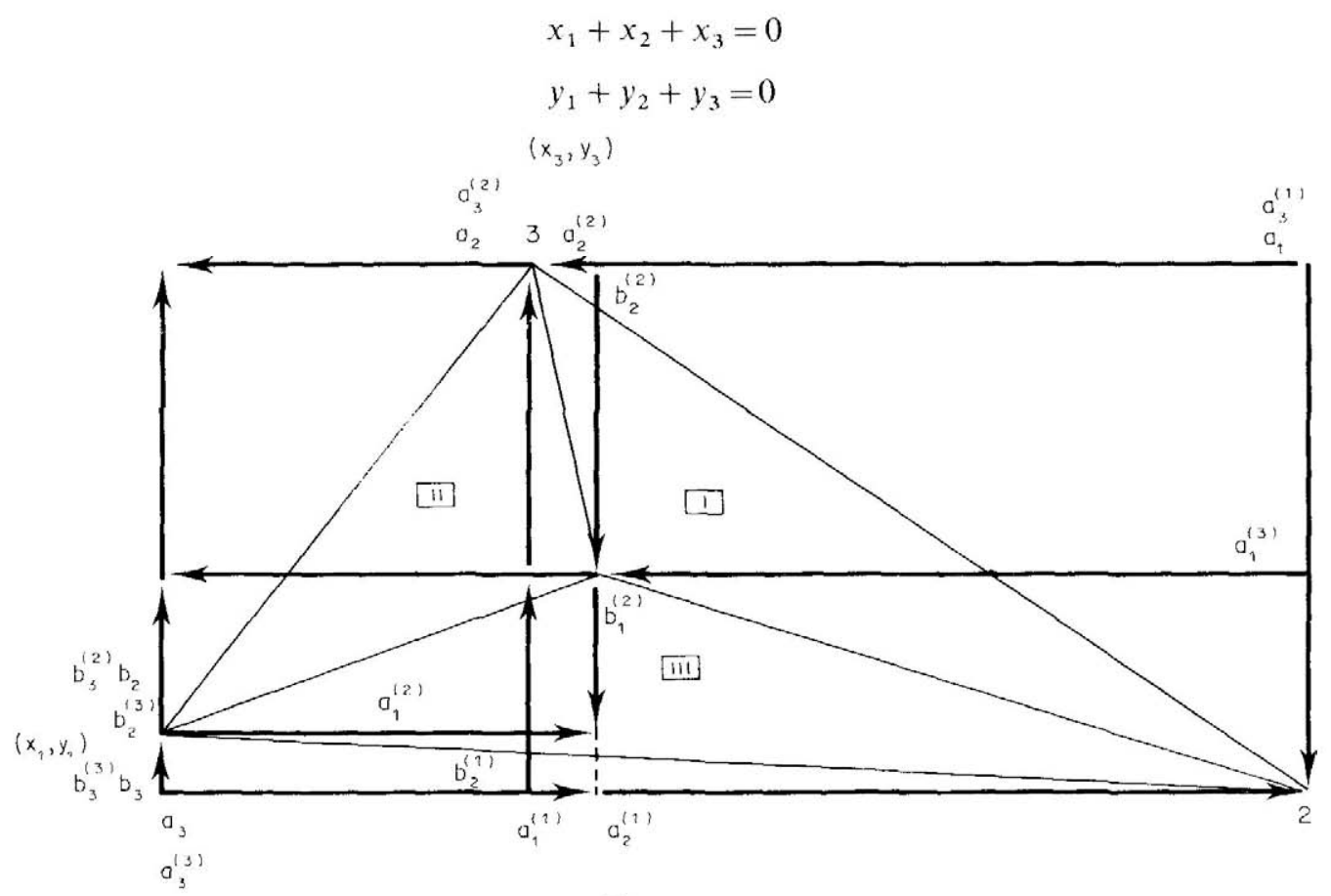

Figure 19 
Thus we have:

$$
\begin{array}{ll}
a_{1}^{(i)}=\frac{a_{j}-a_{i}}{3}, & b_{1}^{(i)}=\frac{b_{j}-b_{j}}{3} \\
a_{2}^{(i)}=\frac{a_{k}-a_{i}}{3}, & b_{2}^{(i)}=\frac{b_{k}-b_{i}}{3} \\
a_{3}^{(i)}=a_{i}, & b_{3}^{(i)} b_{i}
\end{array}
$$

and for the triangular co-ordinates (Figure 20)

$$
\begin{aligned}
L_{i}^{(i)} & =3 L_{i}, & L_{i} & =\frac{L_{i}^{(i)}}{3} \\
L_{j}^{(i)} & =\frac{1}{2}-\frac{3}{2} L_{i}+\frac{L_{j}}{2}-\frac{L_{k}}{2}, & L_{j} & =\frac{1}{2}-\frac{L_{i}^{(i)}}{6}+\frac{1}{2} L_{j}^{(i)}-\frac{1}{2} L_{k}^{(i)} \\
L_{k}^{(i)} & =\frac{1}{2}-\frac{3}{2} L_{i}-\frac{L_{j}}{2}+\frac{L_{k}}{2}, & L_{k} & =\frac{1}{2}-\frac{L_{i}^{(i)}}{6}+\frac{1}{2} L_{j}^{(i)}-\frac{1}{2} L_{k}^{(i)}
\end{aligned}
$$

\section{Expression of a polynomial and its derivatives}

polynomial. If $S(N)=N(N+1) / 2$

$$
p\left(L_{1}, L_{2}, L_{3}\right)=\sum_{\substack{i, j, k=0 \\ i+j+k=N}} \lambda_{i j k} L_{1}^{i} L_{2}^{j} L_{3}^{k}=\sum_{n=1}^{S(N+1)} \alpha N_{n} L N_{n}
$$

where

$$
i=i(N, n), \quad j=j(N, n), \quad k=k(N, n)
$$

Natural derivatives.

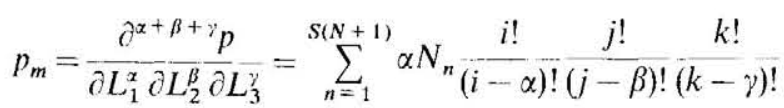

it is a product

$$
L_{1}^{(i-\alpha)} L_{2}^{(j-\beta)} L_{3}^{(k-\gamma)}=\sum_{n=1}^{S(N+1)} \alpha N_{n} \frac{i !}{(i-\alpha) !} \frac{j !}{(j-\beta) !(k-\gamma) !} L N_{n, \alpha \beta \gamma}
$$

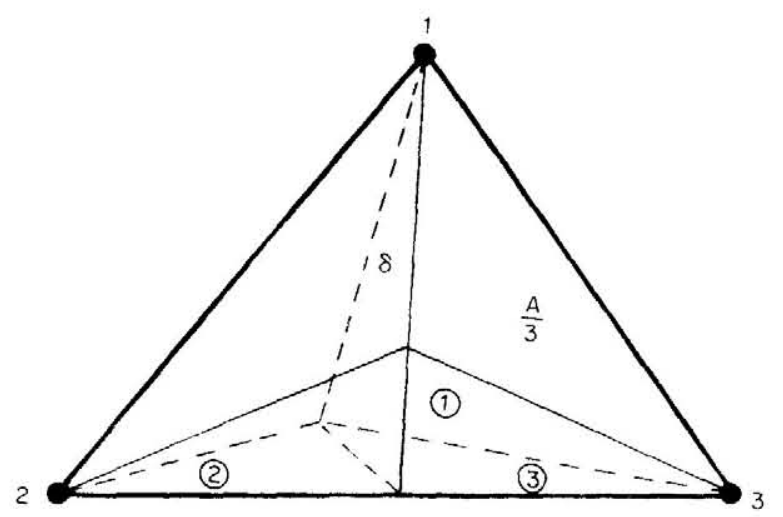

Figure 20 
where

$$
\begin{aligned}
L N_{n, \alpha \beta \gamma} & =0 \quad \text { if } \quad i<\alpha \quad \text { or } \quad j<\beta \quad \text { or } k<\gamma \\
\alpha & =\alpha(m), \quad \beta=\beta(m), \quad \gamma=\gamma(m)
\end{aligned}
$$

General Cartesian derivatives.

$$
\bar{p}_{m}=\frac{\partial^{j+k} p}{\partial x^{j} \partial y^{k}}=\left\{\frac{1}{2 A}\left(b_{1} p_{. L_{1}}+b_{2} p_{. L_{2}}+b_{3} p_{. L_{3}}\right)\right\}^{(j}\left\{\frac{1}{2 A}\left(a_{1} p_{. L_{1}}+a_{2} p_{I_{L_{2}}}+b_{3} p_{. L_{3}}\right)\right\}^{(k}
$$

with

$$
\begin{aligned}
& j=j(m), \quad k=k(m)
\end{aligned}
$$

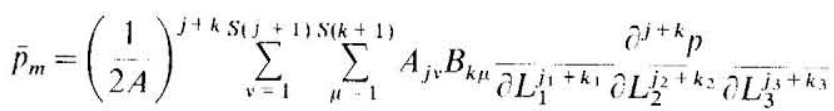

with

$$
\begin{aligned}
& A_{j v}=\frac{j !}{j_{1} ! j_{2} ! j_{3} !} h_{1}^{j_{1}} h_{2}^{j_{2}} h_{3}^{j_{3}} \\
& B_{k \mu}=\frac{k !}{k_{1} ! k_{2} ! k_{3} !} a_{1}^{k_{1}} a_{2}^{k_{2}} a_{3}^{k_{3}}
\end{aligned}
$$

and

$$
\begin{array}{lll}
j_{1}=j_{1}(j, v), & j_{2}=j_{2}(j, v), & j_{3}=j_{3}(j, v) \\
k_{1}=k_{1}(k, \mu), & k_{2}=k_{2}(k, \mu), & k_{3}=k_{3}(k, \mu)
\end{array}
$$

Local Cartesian derivatines.

$$
\begin{aligned}
\hat{p}_{m}^{i}=\frac{\partial^{i+h} p}{\partial s_{i}^{j} \lambda n_{i}^{k}}= & \left\{\frac{1}{2 A}\left(a_{i 1} p_{L_{1}}+a_{i 2} p_{L_{2}}+a_{i 3} p_{L_{3}}\right)\right\}^{j} \\
& \times\left\{\frac{1}{2 A}\left(b_{i 1} p_{L_{1}}+b_{i 2} p_{L_{2}}+b_{i_{3}}, p_{L_{3}}\right)\right\}
\end{aligned}
$$

with

$$
\begin{aligned}
& j=j(m), \quad k=k(m) \\
& a_{i i}=0, \quad a_{i, j}=-H_{i}, \quad a_{i h}=H_{i} \quad \text { and } \quad\left(0^{\prime \prime}=1\right) \\
& h_{i i}=e_{i}, \quad h_{i j}=f_{i}, \quad b_{i k}=d_{i}
\end{aligned}
$$

and $i$ is the number of side.

$$
\bar{p}_{m}^{i}=\left(\frac{1}{2 A}\right)^{j+k} \sum_{v=1}^{S(j+1)} \sum_{\mu=1}^{S(k+1)} \bar{A}_{j v}^{i} \bar{B}_{k^{\mu}}^{i} \partial L_{1}^{j_{1}+k_{l}} \frac{\hat{c}^{j+k} p}{\partial L_{2}^{j_{2}+k_{2}} \partial L_{3}^{j_{3}+k_{3}}}
$$

with

$$
\bar{A}_{j v}^{i}=\frac{j !}{j_{1} ! j_{2} ! j_{3} !}\left(a_{i 1}\right)^{j_{1}}\left(a_{i 2}\right)^{j_{2}}\left(a_{i 3}\right)^{j_{3}}
$$




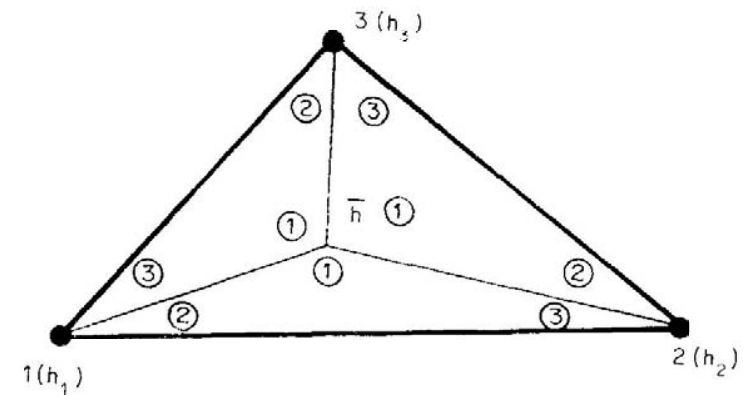

Figure 21. Thicknesses

$$
\bar{B}_{k \mu}^{i}=\frac{k !}{k_{1} ! k_{2} ! k_{3} !}\left(b_{i 1}\right)^{k_{1}}\left(b_{i 2}\right)^{k_{2}}\left(b_{i 3}\right)^{k_{3}}
$$

and

$$
\begin{array}{lll}
j_{1}=j_{1}(j, v), & j_{2}=j_{2}(j, v), & j_{3}=j_{3}(j, v) \\
k_{1}=k_{1}(k, \mu), & k_{2}=k_{2}(k, \mu), & k_{3}=k_{3}(k, \mu)
\end{array}
$$

\section{Thickness}

The variation of thickness can be modelied as follows (Figure 21):

$$
\bar{h}=h\left(\frac{1}{3}, \frac{1}{3}, \frac{1}{3}\right)=\frac{h_{1}+h_{2}+h_{3}}{3}
$$

In the subelement number $i$ :

$$
h^{(i)}\left(L_{1}^{(i)}, L_{2}^{(i)}, L_{3}^{(i)}\right)=\bar{h} L_{1}^{(i)}+h_{j} L_{j}^{(i)}+h_{k} L_{k}^{(i)}
$$

\section{RFFERENCES}

1. O. C. Zienkiewicz. The Finite Element Methos in Engineeriny Science, McGraw-Hill, London, 1979.

2. A. Adini and R. W. Clough, 'Analysis of plate bending by the finite element method', A Report to the National Science Foundation. U.S.A., G. 7337. 1961.

3. G. P. Bazeley, Y. K. Cheun. B. M. Irons and O. C. Zienkiewicz. 'Triangular elements in bending conforming and nonconforming solution: Proc. Conf. Matrix Methods in Struct. Mech., Air Force Inst. of Tech., Wright-Patterson A. F Base, Ohio. October 1965.

4. B. M. Irons, The patch test for enginecrs', Conf. Allas Computiny Centre, Harwell U.I. March 1974.

5. B. M. Irons and M. Loikkanen, 'An engineers' defence of the patch test', Int. j. numer. methods eng., 19, 1391 140)! (1983).

6. B. M. Irons and J. K. Draper, 'Inadequacy of nodal connections in a stiffness solution for plate bending', I.A.I.A.A., 3, S (1965).

7. J. L. Batoz, K. J. Bathe and 1. W. Ho, A study of three-node triangular plate bending elements', Imt. j. mamer. methods ('n) $1 . .15,1771 \quad 1812(1980)$.

8. A. K. Noor and W. D. Plikey. 'State of the art surveys of finite element methods', AMD Special Publication, 1981.

9. A. Pano, Conforming approximations for Kirchhoff plates and shells', Int. j. numer. methods eng.. 14,1273 1291 $(1979)$.

10. A. Samartin. A plicacion del método de los elementos finitos al analisis estructural de puentes", Discurso de inturefuracion de (urso Acudémico 1979 80, Universidad de Santander. 1979

11. J. F. Moya, P. Fuster and S. Monleón. 'Una teoría variacional para el análisis de liminas liperelásticas basada en una jerarquizacion a orden $\mathrm{N}$ del modelo cinematico transversal. Aplicacion de primer orden al estudio del comportamiento no lineal y de la cstablidad, E.T.S. de Ing. de (aminos, Universidad Politécnica de Valencia, Junio I984.

12. R. W. Clough and J. L. Tocher. 'Finite element stiffness matrices for analysis of plate bending', Proc. Conf. Matrix 
Methods in Struct. Mech., Air Force Inst. of Tech., Wright-Patterson A.F. Base, Ohic. 1965.

13. R. Clough and C. Felippa. 'A refined quadrilateral element for analysis of plate bending', Proc, II. Conf. Matrix Meihods in Struct. Mech., Air Force Inst. of Tech., Wright-Patterson A.F. Base, Ohio, 1968

14. A. Samartín, Un estudio sobre la exacitud del método de los elementos finitos. Aplicación a la barra de sección variable bajo esfuerzos axiles'. Universidad de Santander. Noviembre de 1980.

15. J. Torres, 'Una familia de elementos simples conformes clasc $C^{\prime}$, Ph.D. Dissertation, Dept. de Análisis de la Estructuras. F.T.S. de Ing. de Caminos de Santander, 1984.

16. T. H. Evans, Journal Appl. Mechunics. 6, A-7 (1939)

17. J. Díaz del Valle and A. Samartin, 'Una contribución al estudio de hiperelementos finitos en placas'. Ph.D. Dissertation, Departamente de Analisis de las Fstructuras de la E.T.S. de Ing. de (aminos, Santander. 1980.

18. U. P. Jensen, Bulletin 3.32, Illinots University, 1941

19. S. Timoshenko and S. Woinowsky-Krieger, Theory of Plates and Shells, McGraw-Hill, 2nd edn, 1959.

20. A. Vegmulier, 'Finite element analysis of elastic plastic plates and eccentrically stiffened plates', Ph.D. Disserlation. Civil Fng. Dept. Lehigh University, 1971.

21. R. J. Melosh, 'A stiffness matrix for the analysis of thin plates in bending. Journal of Aeronautical Sciences, 28, 34 (1961).

22. S. W. Papperfusn, 'Lateral plate deflection by stiffness matrix methods with application to a marqee'. M.S. Thesis, Dept. of Civil Fng., University of Washington, Seatle 1969.

23. F. K. Bogner, R. L. I ox and L. A. Schmit, The generation of interelement compatible stiffness and mass matrices by the use of interpolation formulas, Proc. First. Conf. on Matrix Methods in Siruct. Mech., Wright-Patterson A.F. Base, Ohio, November 1965.

24. M. Gasca and J. 1. Macztu, 'On Lagrange and Hermite interpolation in $R^{k}$, Numer. Math., 39, 1 14 (1982).

25. J. García de Jalón, 'Contribución a la resolución numérica del problema termoelástico en sólidos con simertía de revolucion', Ph.D. Dissertation, F.T.S. Ing. Industriales, San Scbastián, 1977.

26. B. M. Irons. A conforming quartic triangular clement for plate bending: Int. j. numer. methods enc.. 1, 29. 45 (1969). 